\title{
Management of Retinal Vein Occlusion - Consensus Document
}

\author{
Gabriel Coscas $^{\mathrm{a}}$ Anat Loewenstein $^{\mathrm{b}}$ Albert Augustin $^{c}$ Francesco Bandello $^{\mathrm{d}}$

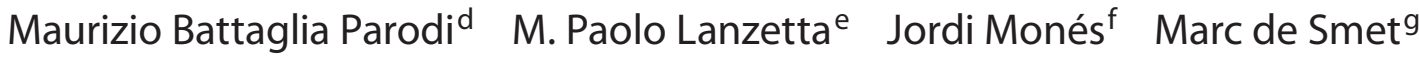 \\ Gisèle Soubrane $^{\text {a }}$ Giovanni Staurenghi ${ }^{\text {h }}$ \\ ${ }^{a}$ Hôpital Intercommunal de Créteil, Service Universitaire d'Ophtalmologie, Créteil, France; ${ }^{b}$ Department of \\ Ophthalmology, Tel Aviv Medical Center, Sackler Faculty of Medicine, Tel Aviv University, Tel Aviv, Israel;

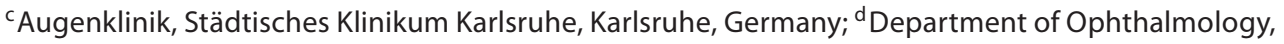 \\ Scientific Institute San Raffaele, Milan, e Department of Ophthalmology, University of Udine, Udine, Italy; \\ ${ }^{f}$ Institut de la Màcula i de la Retina, Centro Medico Teknon, Barcelona, Spain; ${ }^{9}$ Department of Ophthalmology,

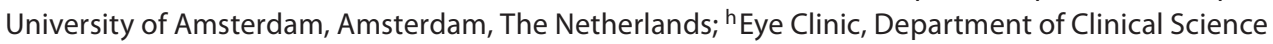 \\ 'Luigi Sacco', Sacco Hospital, University of Milan, Milan, Italy
}

\section{Key Words}

Retinal vein occlusion $\cdot$ Consensus document

\begin{abstract}
Retinal vein occlusion (RVO) can have severe consequences for the people affected by the disease, including visual loss with costly social repercussions. Currently, there is no European consensus with regard to the management of RVO. Following a careful review of the medical literature as well as the data from several clinical trials, a collaborative group of retina specialists put forth practical recommendations based on the best available scientific evidence for the clinical approach to RVO. Taking into consideration the recent advances in diagnostic tools and management options, the present document aims to provide the European ophthalmologists with guidelines for clinical practice to the benefit of their patients.

Copyright $\odot 2011$ S. Karger AG, Basel
\end{abstract}

\section{Introduction}

Retinal vein occlusion (RVO) has been defined as a retinal vascular disorder characterized by engorgement and dilatation of the retinal veins with secondary, mostly intraretinal hemorrhages and intraretinal edema, retinal ischemia including cotton wool spots, retinal exudates and macular edema [1-8]. As soon as the foveal region is affected by macular edema, central visual acuity (VA) drops, leading to a progressive, or sometimes acute, painless loss in vision.

$\mathrm{RVO}$ is a common cause of visual loss in the Western world. RVO is the second most common cause of reduced vision due to retinal vascular disease, just after diabetic retinopathy $[9,10]$, with branch retinal vein occlusion (BRVO) occurring 2-3 times more often than central retinal vein occlusion (CRVO) $[11,12]$. The incidence of vein occlusion was reported to be $0.7 \%$ for the age group of 49 to 60 -year-olds, and $4.6 \%$ after the age of 80 years. It is currently estimated that there are about 520 new RVO cases per million people [13], of which 442 are BRVO cas-

Prof. Gabriel Coscas

Hôpital Intercommunal de Créteil, Service Universitaire d'Ophtalmologie

40 , avenue de Verdun

FR-94010 Créteil (France

E-Mailgabriel.coscas@gmail.com 
es and 80 CRVO cases. RVO typically occurs in middleaged and elderly individuals (older than 50 years), with an equal gender distribution.

The etiology of RVO is still incompletely known. An external compression of the vein wall is suggested, in CRVO at the level of the lamina cribrosa, in BRVO at the level of arteriovenous crossing. Many additional factors may occur, including a partial obstruction of the retinal venous system by thrombus formation $[9,14,15]$.

RVO are differentiated by their location into: (1) CRVO if the whole venous retinal system is involved and the presumed site of increased venous outflow resistance is located in, or posterior to, the lamina cribrosa, and (2) BRVO if the venous engorgement involves only branches of the retinal venous network. It can be limited to a small peripheral arteriovenous crossing or involve a whole quadrant when occurring at the edge of the optic nerve. If the superior or the inferior hemisphere of the fundus is involved, the presumed site of the occlusion is one of the two trunks of the intraneural central retinal vein when this congenital abnormality exists. This entity (hemicentral RVO) is considered a variant of CRVO [9, $14,15]$.

CRVO is classically characterized by disk edema, increased dilatation and tortuosity of all retinal veins, widespread deep and superficial hemorrhages, cotton wool spots, retinal edema and areas of capillary nonperfusion. It is classically divided into 'perfused' (nonischemic) and 'nonperfused' (ischemic). BRVO has similar features, but these are confined to only a section of the retina [16].

In view of the significant ophthalmological and medical consequences of RVO, these guidelines drafted by a panel of European experts promote a good standard of practice and the achievement of best visual and medical outcomes. This document aims to provide updated recommendations on the management of RVO in the light of recent advances in the diagnosis and treatment of both BRVO and CRVO. It is intended to be used by ophthalmologists as well as by general physicians.

\section{Methods}

A group of 9 retina specialists from all over Europe, who are opinion leaders in medical retinal diseases, constituted the RVO Guidelines Development Group. The group consisted of: Gabriel Coscas and Gisèle Soubrane, France; Anat Loewenstein, Israel; Francesco Bandello, Giovanni Staurenghi and Paolo Lanzetta, Italy; Albert Augustin, Germany; Jordi Monés, Spain, and Marc de Smet, Switzerland. The guidelines were discussed and endorsed by an additional group of 10 retina specialists: José Sahel, France; Sebastian Wolf and Thomas Wolfensberger, Switzerland; Victor Chong and Adnan Tufail, UK; Anselm Kampik and Jost Jonas, Germany; Borja Corcostegui, Spain; Urban Eriksson, Sweden, and José Cunha-Vaz, Portugal. For the purpose of this review, literature searches were performed in the MEDLINE/PubMed and Cochrane Library databases (cutoff date: December 2010).

\section{Pathophysiology}

\subsection{Branch Retinal Vein Occlusion}

In the majority of cases, BRVO occurs at retinal arteriovenous crossing sites sharing a common adventitia [9]. In nearly all cases, the artery lies anterior to the vein, making the vein vulnerable to compression by the artery, resulting in turbulent flow, which in turn leads to a predisposition toward endothelial damage and thrombus formation $[10,11]$. This process is exacerbated in the presence of arteriosclerosis $[9,10,12,17]$. Turbulent flow at arteriovenous crossing sites has been demonstrated by fluorescein angiography [5].

\subsection{Central Retinal Vein Occlusion}

Several hypotheses exist regarding the pathogenesis of CRVO. The central retinal vein may be compressed by the central retinal artery since they share a common fibrous sleeve [17]. Degenerative or inflammatory disease of the central retinal vein wall, as well as hemodynamic factors such as hypotension and blood dyscrasia, may also play a role [17-20]. Stagnation of venous blood flow, leading to the formation of a thrombus, is the final common pathway of all these mechanisms. Histopathologic studies demonstrate that thrombus formation in all or most CRVO cases takes place at the lamina cribrosa or just posterior to it [14]. The perfused type of CRVO is thought to occur more posteriorly to the lamina cribrosa, where the increased availability of collateral channels results in less complete occlusion [18].

\section{Risk Factors}

\subsection{Ophthalmological Risk Factors: Glaucoma}

Open-angle glaucoma is the most common ocular factor predisposing subjects to RVO. The increased intraocular pressure is thought to compromise retinal vein 
outflow and produce stasis $[26,29,41]$. Recent evidence points to an association between CRVO and glaucoma $[40,42]$. An association of BRVO with glaucoma has also been reported in one study [29].

\subsection{Systemic Risk Factors}

Established cardiovascular risk factors are most often medically associated with both central and branch vein occlusions [18, 21, 22]. Virchow's triad established the cardiovascular thrombogenic risk factors of vessel damage, stasis and hypercoagulability [23]. In patients over 50 years of age, a cardiovascular risk factor is usually present. In patients younger than 50 years of age, an obvious risk factor is absent in $60 \%$ of cases $[24,25]$. More than $90 \%$ of cases of RVO occur in the age group over 50 years [23].

\subsubsection{Hypertension and Cardiovascular Disease}

A common finding is a recently diagnosed or uncontrolled hypertension. This major risk factor is more prevalent in patients with BRVO than in those with CRVO. More than $64 \%$ of RVO patients in the age group over 50 years are hypertensive, and it is a predominant finding in recurrent RVO $(88 \%)[26,27]$. Likewise, vascular events (cardiovascular, cerebral) are observed more often in patients with preexisting RVO [27].

\subsubsection{Hyperlipidemia and Hypercholesterolemia}

This is the predominant risk factor for RVO in patients under 50 years old. It is also found in up to $50 \%$ of older patients [28]. It was reported that $71.4 \%$ of all patients tested with RVO do have hypercholesterolemia [29].

\subsubsection{Diabetes Mellitus}

Diabetes mellitus is significantly associated with CRVO [30]. It was not, however, found to be an independent risk factor for BRVO [29, 31-38], possibly because of an increased presence of confounding coexisting cardiovascular risk factors in these patients $[26$, $29,39]$.

\subsubsection{Other Vascular Risk Factors}

High body mass index and smoking have also been implicated in RVO, but these associations are less consistent $[28,33,40]$.

\subsubsection{Thrombophilia}

Initial information about the risk from coagulopathies comes from retrospective studies and case reports [23]. In fact, the role of thrombophilic defects in the development of RVO was first proposed when elevated levels of homocysteine were observed in patients with RVO. However, an association to the C677T dimorphism in the methylenetetrahydrofolate reductase gene could not be established $[9,11]$. Two meta-analyses showed that the factor $\mathrm{V}$ Leiden mutation increases the risk of RVO by about $50-60 \%[9,12]$, whereas other prothrombotic defects - i.e. prothrombin G21201A and deficiencies of antithrombin and of protein $\mathrm{C}$ or $\mathrm{S}$ - are not associated with RVO [9].

The role of lupus anticoagulant and anticardiolipin antibodies in RVO is uncertain [9, 10, 13, 43-51]. The relationship between fibrinolysis and RVO has not received much attention, but so far does not show to be strong [10, 15, 16]. Since RVO occurs at arteriovenous crossings, where the blood flow is locally turbulent, changes in platelet reactivity due to polymorphisms in the platelet receptors may be important. One study suggests that there may be some genetic predisposition in patients with RVO.

Since thrombophilic defects are mainly of genetic origin (except hyperhomocysteinemia, which is dietary in nature), a family history of thrombotic events (deep venous thrombosis, pulmonary emboli or multiple spontaneous abortions) can often be revealing. Screening patients with such a history entails a better chance of identifying patients at risk.

\subsubsection{Rarer Associations}

Findings such as oral contraceptives and optic disk vasculitis are more prominent in younger patients (less than 50 years old) [24, 52]. There is a lack of consensus with regard to the roles of these factors, with some researchers claiming that they are not significant risk factors $[53,54]$. 


\subsubsection{Other Observations}

Myeloproliferative disorders (such as lymphoma and leukemia) are found in $1 \%$ of patients presenting with RVO [30]. Other rare associations with RVO are inflammatory diseases that cause or are associated with retinal vasculitis. Often in this setting, the RVO presents adjacent to a site of retinal granulomatous infiltration or in a peripheral distribution with involvement of multiple small vessels. It also tends to affect younger individuals. Among the diseases to consider are sarcoidosis, toxoplasmosis, tuberculosis, Behçet's disease, systemic lupus erythematosus, polyarteritis nodosa, Wegener's granulomatosis and Goodpasture's syndrome [23]. Recently, an association with sleep apnea has been reported [55].

\subsubsection{Summary}

The proven association of RVO with systemic vascular diseases emphasizes the need to screen new patients for vascular risk factors such as hypertension, dyslipidemia and diabetes. Treatment of these underlying causes is of paramount importance in preventing considerable morbidity. An investigation of thrombophilia should be considered when no other obvious etiology is present [23].

\section{Natural History of RVO}

\subsection{Central Retinal Vein Occlusion}

\subsubsection{Visual Acuity}

Natural history reported by the Central Vein Occlusion Study (CVOS) Group $[8,56]$ and a systematic literature review [57] testify to a generally poor visual outcome in CRVO. The VA at presentation has a key prognostic significance:

- eyes with an initial VA of 20/40 or better have a more favorable visual prognosis than those with a worse initial VA;

- only $20 \%$ of eyes with an initial VA between $20 / 50$ and 20/200 improve spontaneously to 20/50, while

- $80 \%$ of patients whose baseline vision is worse than 20/200 remain at this level or deteriorate further [56]. Loss of VA is usually more pronounced with ischemic than with nonischemic CRVO, although vision also tends to be poor in eyes with the nonischemic type [57]. The
CVOS reported that $63 \%$ of nonischemic eyes had VA scores of less than 20/40 [7].

The Standard Care vs. Corticosteroid for Retinal Vein Occlusion (SCORE) study reported that at least $75 \%$ of eyes (ischemic and nonischemic CRVO) in the observation group had VA of 20/40 or worse after 12 months [58].

The Ozurdex ${ }^{\circledR}$ GENEVA study found that only $7.5 \%$ of patients (ischemic and nonischemic CRVO) in the observation group had improved vision by at least 15 letters from baseline after 30 days of treatment initiation when tested 30 days after CRVO, and this percentage increased to $17.6 \%$ after 180 days [59]. A meta-analysis by McIntosh et al. [57] reported that the mean decrease in VA for ischemic CRVO was 35 letters after 12 months or longer follow-up, compared to a decrease of an average of 3 letters over a follow-up of at least 12 months in nonischemic CRVO.

\subsubsection{Conversion from Ischemic to Nonischemic CRVO}

Fluorescein angiography helps to detect and evaluate an extension of a perfused or nonperfused area (capillary exclusion zone), not only at the periphery but also at the posterior pole with enlargement of the foveal avascular zone. While these changes are irreversible, the ischemia observed initially may be only relative: delayed circulation resulting from vascular stasis as well as inflammation of the vessel wall are reversible with the development of collaterals.

A conversion rate from ischemic to nonischemic CRVO over 18 months has been initially reported [18]. Conversion rates of $12.6 \%$ reported in other studies ranged from 0 [60] to $27 \%$ [61] during a follow-up varying from 10 weeks to 13 months after CRVO. The CVOS [55] reported that in the first 4 months of follow-up, 81 (15\%) of 547 eyes with good perfusion converted to ischemia. During the next 32 months of follow-up, additional 19\% of eyes were found to have converted to ischemia, for a total of $34 \%$ after 3 years. The development of nonperfusion or ischemia was most rapid in the first 4 months and progressed continuously throughout the entire duration of follow-up.

\subsubsection{Neovascularization}

The incidence of neovascularization secondary to (initially) nonischemic CRVO has been found to vary from 0 

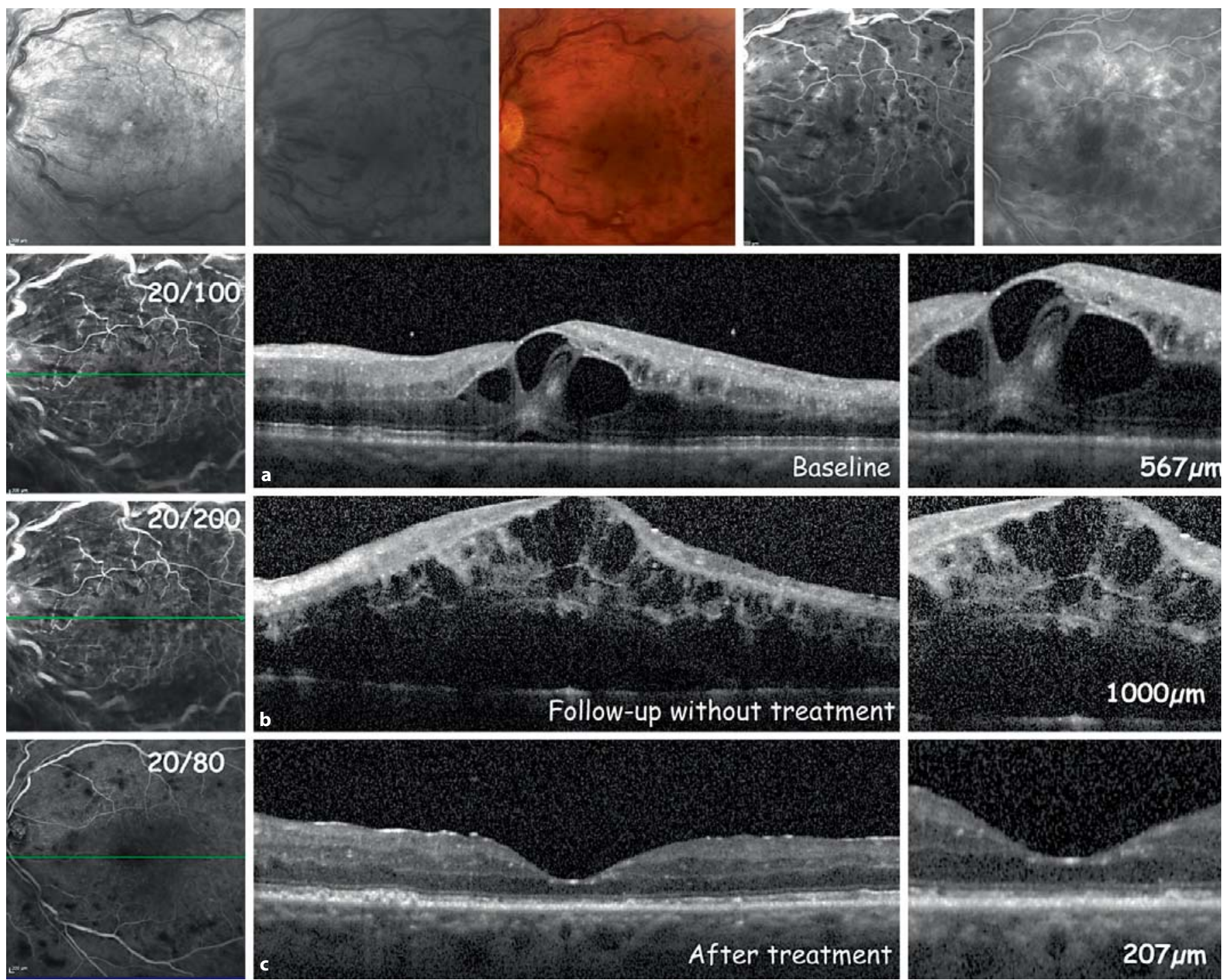

Fig. 1. Well-perfused central vein occlusion with macular cystoid edema. Before and after treatment. Intravitreous injection of dexamethasone implant. a Before intravitreal Ozurdex injection. Fluorescein angiography shows a relatively well-perfused macular cystoid edema. The spectral domain optical coherence tomography shows increased thickness of the retina, with central retinal thickness (CRT) at $567 \mu \mathrm{m}$. Many large central cystoid spaces and extensive retinal detachment with subretinal fluid accumulation can be seen. $\mathbf{b}$ Three-month follow-up. Increase in CRT to 1,000 $\mu \mathrm{m}$ and dramatic extension of the cystoid spaces and subretinal fluid associated with drop in vision (20/200). c Four-month follow-up after Ozurdex injection. CRT progressively normalized (to $207 \mu \mathrm{m})$. The foveal depression became quite normal without cystoid spaces or subretinal fluid. The hyperreflective dots disappeared, and the external limiting membrane became clearly visible. to $33 \%$ over $12-15$ months [57]. In one study [62] in which the CRVO subtype was not classified, an incidence as high as $50 \%$ was reported at 6 months after CRVO. The strongest predictors of anterior segment (iris or angle) neovascularization were VA and the extension of nonperfused areas, seen by fluorescein angiography. In the CVOS, of those eyes initially categorized as nonperfused or indeterminate, $35 \%(61 / 176)$ developed iris or angle neovascularization, compared with $10 \%$ of eyes $(56 / 538)$ initially categorized as perfused [56].

Ischemic CRVO is associated with a higher risk of neovascular glaucoma, which was reported to develop in at least $23 \%$ of cases within 15 months [57]. Neovascularization is first detected by gonioscopy as a fine vascular net- 
work adjacent to the trabecular meshwork. Next, it can be seen at the pupillary margin, where a fine vascular network causes an ectropion uveae. These occur before closure of the angle and neovascular glaucoma. A 10\% incidence of post-CRVO vitreous hemorrhage has been documented at 9 months [63].

\subsubsection{Macular Edema}

Macular edema is a major complication of both ischemic and nonischemic CRVO. Most studies reported the presence of macular edema at baseline. There are too few reported cases of macular edema developing after RVO to make statements on incidence rates. They include the report of a $0-73 \%$ resolution for the ischemic type, and of about $30 \%$ for the nonischemic type over 2-15 months [57].

Chronic macular edema is associated with poor visual prognosis but needs to be treated (fig. 1). Early intervention is justified by the finding that the longer the duration of edema, the greater the likelihood of structural damage to the fovea [57]. The Ozurdex GENEVA study showed that although improvement in the sham group was greater with shorter duration of macular edema, the response to treatment was not dependent on time [59].

\subsubsection{Fellow-Eye Involvement}

The existence of systemic risk factors makes the fellow eye similarly vulnerable. Approximately $5-10 \%$ of CRVO cases were reported to develop RVO in the fellow eye over a 1-year period [57, 64-67].

\subsection{Branch Retinal Vein Occlusion}

\subsubsection{Visual Acuity}

Vision at presentation in eyes with BRVO is generally worse than 20/40. Although it generally improves (in one report from an average of 1 letter at 6 weeks to 28 letters at 24 months) [68], significant improvement beyond 20/40 is rare [69]. The Branch Vein Occlusion Study (BVOS) reported that $20 \%$ of untreated eyes experienced significant visual deterioration over time. Approximately $50 \%$ of untreated eyes with BRVO retained a VA of $6 / 12$ or better, while in $25 \%$ of cases, final VA was less than $6 / 60[70,71]$.

Management of RVO - Consensus Document

\subsubsection{Neovascularization}

The incidence of neovascularization is relatively low in BRVO, except in cases with extensive (more than one third of the fundus) ischemia. But there is a lack of meaningful studies on the incidence of neovascularization in BRVO patients [69].

\subsubsection{Macular Edema}

Few data are available on the incidence of macular edema. Macular edema may develop in $5-15 \%$ of eyes over a 1-year period [69]. Another study reported an incidence of $15 \%$ at 7.5 months following the onset of BRVO [72]. Of eyes with macular edema at presentation, $18 \%$ achieved resolution by 4.5 months, and $41 \%$ by 7.5 months. Unlike for CRVO, the Ozurdex GENEVA study showed improvement in treatment groups as well as the sham group with shorter macular edema duration (fig. 2) [59].

\subsubsection{Fellow-Eye Involvement}

Bilateral involvement at recruitment to studies has been reported in $4.5-6.5 \%$ of patients $[2,73]$. The BVOS reported a rate of $9 \%$ of bilateral involvement, although it is unclear if both eyes were involved at presentation or whether bilateral involvement developed over time [70, 71]. Michels and Gass [74] reported a 10\% development of $\mathrm{BRVO}$ in the fellow eye over time. Cross-sectional population data suggest a 5\% bilateral involvement [40, 64-67].

\section{Management}

The management of RVO is centered on two main objectives: (1) the identification of modifiable risk factors and their medical management, and (2) the recognition and management of sight-threatening complications.

\subsection{Medical Management}

\subsubsection{Systemic Risk Factors}

Management of RVO should address several targets including the identification and management of systemic risk factors (specifically hypertension, cardiovas-

Ophthalmologica 2011;226:4-28 

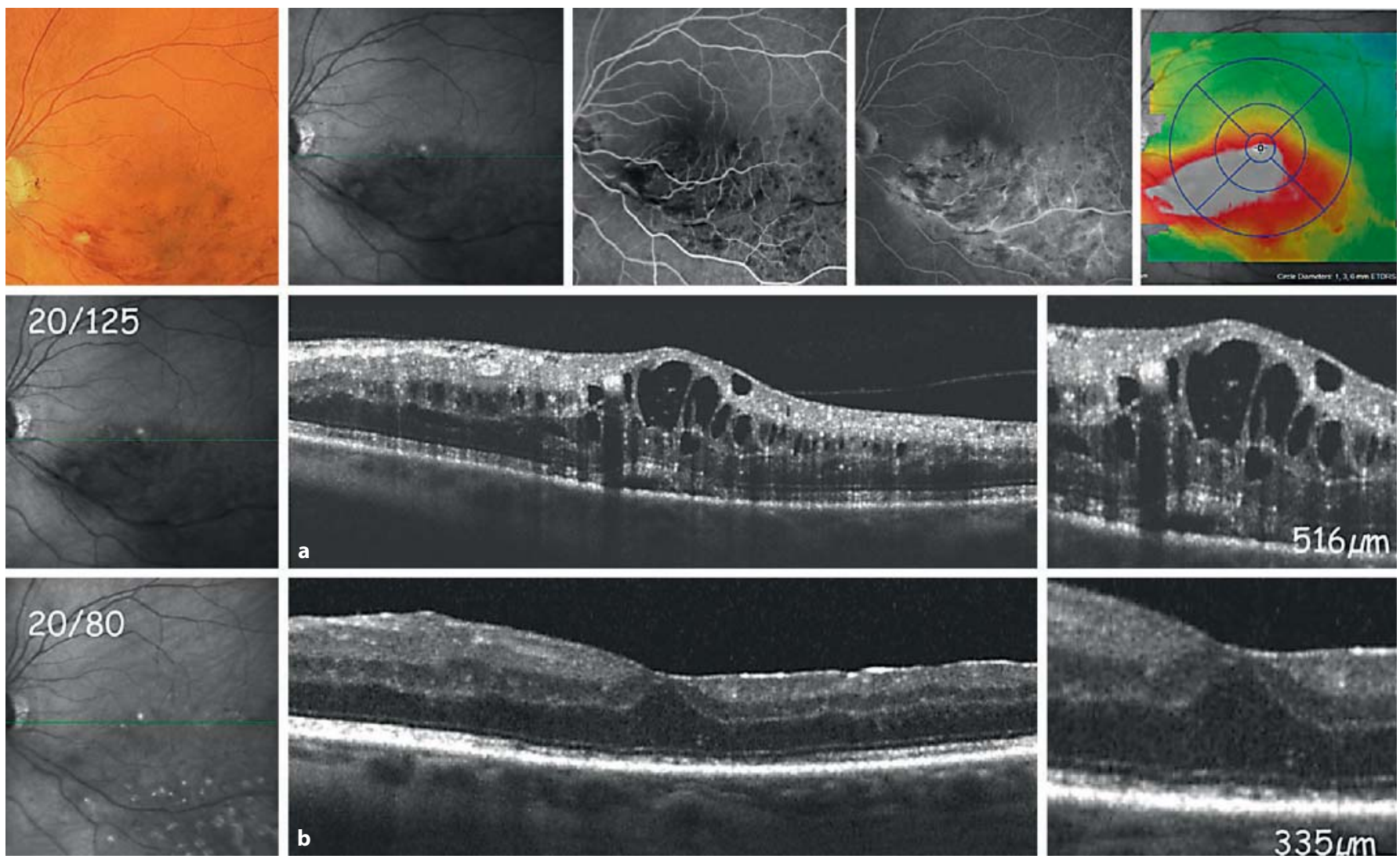

Fig. 2. BRVO with macular cystoid edema. Before and after treatment. Intravitreous injection of dexamethasone implant. a Baseline. Branch vein occlusion, localized at an arteriovenous crossing at 1 disk diameter from the disk, associated with numerous hemorrhages and macular cystoid edema limited to the inferior half of the central avascular zone. The spectral domain optical coherence tomography section shows the central retinal thickness (CRT) at $516 \mu \mathrm{m}$ and a limited subretinal detachment. The external limiting membrane is still visible, but the inner/ outer segment interface is thickened and hyperreflective. A number of hyperreflective dots are present. b Four-month follow-up. Complete fluid regression and flattening of the retina $(\mathrm{CRT}=335 \mu \mathrm{m})$. The outer nuclear layer became quite normal, the hyperreflective dots disappeared, the external limiting membrane and the inner/outer segment interface became regular and clearly visible; the retinal pigment epithelium layer was normal. VA: 20/80. cular disease, diabetes mellitus, hyperlipidemia and thrombophilia). Treatment of underlying medical conditions is required to prevent nonocular events, e.g. myocardial infarcts and cerebrovascular events $[75,76]$, and to reduce the risk of venous occlusion in the fellow eye [77].

Medical investigations of underlying systemic risk factors are recommended in the presence of ocular findings associated with RVO (dilated retinal veins and few scattered hemorrhages without any macular edema in asymptomatic patients or in patients with transient episodes of blurring who may have a slight increase in retinal circulation time on fluorescein angiography). Prompt initiation of treatment for underlying medical conditions may avert the progression or resolve the existing occlusion [78].

Since the population-based studies mentioned above, as well as multicenter prospective studies such as the CVOS have shown associations between RVO and glaucoma or arterial hypertension $[7,26,29,37,40,56]$, these conditions should be excluded, or if present, treated accordingly. So far, it has remained unclear whether a lowering of intraocular pressure in the case of glaucoma patients, or a better control of blood pressure in the case of patients with arterial hypertension, is beneficial to the final visual outcome after RVO. 


\subsubsection{Anticoagulants, Fibrinolytic Agents and Antiplatelet Drugs}

These would seem to be logical treatments, but results from trials using heparin, streptokinase and warfarin have been disappointing, with limited evidence of any benefit owing to adverse effects of retinal and vitreous hemorrhage. Aspirin is not recommended for primary prevention of cardiovascular events. Given that there is insufficient evidence to suggest that RVO is a risk factor for stroke or vascular mortality, the role of aspirin in RVO remains equivocal.

\subsubsection{Hemodilution}

Several studies have suggested a beneficial effect of hemodilution as a therapy in the early phase of RVO. Hemodilution is expected to prevent the slowdown of blood circulation and its complications by dramatically lowering blood viscosity. Some randomized studies have been published on the topic and concluded on a statistically significant difference between treated and nontreated patients [61, 79-82]. Nevertheless, these monocenter studies were conducted in the 1980s and 1990s, and they used different treatment protocols.

A recent prospective multicenter study using a new method of hemodilution, erythrocytapheresis, confirmed these positive results. Hemodilution should therefore be recommended in recent-onset CRVO and BRVO when there are no contraindications to treatment (including ischemic forms of CRVO requiring panretinal laser photocoagulation, diabetes, uncontrolled systemic hypertension, severe cardiac or renal failure, anemia and sickle cell disease) [83].

\subsection{Ophthalmological Management}

Although the systemic investigations and treatment are identical for all types of vein occlusion, the ophthalmological management of CRVO and that of BRVO differ. Both of them will therefore be considered separately. The latest breakthrough in the management of RVO is the dexamethasone intravitreal implant (Ozurdex) has received its FDA and EU licenses for the treatment of RVO. These were based on the Ozurdex GENEVA study results [59]. Ranibizumab has recently received FDA approval for the treatment of RVO in the USA $[84,85]$, but has not been approved yet by the EMA (European Medicines Agency).

\subsubsection{Management of CRVO}

\subsubsection{Classification of CRVO Subtypes}

The first step in CRVO management is represented by the differential diagnosis between nonischemic (or well perfused) CRVO and ischemic CRVO, with an evaluation of nonperfused capillary areas at the posterior pole and of the presence/extension of nonperfused zones at the periphery on fluorescein angiography. The indications for treatment of sight-threatening complications by means of both systemic and ophthalmological management of CRVO are based on this differentiation.

In nonischemic CRVO, major vision-threatening complications are macular edema and conversion to ischemia. In ischemic CRVO, a major vision-threatening complication is the development of ocular neovascularization, especially in the anterior segment of the eye (iris and angle, up to neovascular glaucoma). Macular edema can occur in all forms of CRVO.

Even though the differentiation between ischemic and nonischemic may be difficult, at least initially or at early stages, many clinical and functional features that are typical of ischemic CRVO can guide the diagnosis $[3,8,13,56$, 86]. The findings include: poor VA; relative afferent pupillary defect; presence of multiple dark, deep intraretinal hemorrhages; presence of multiple cotton wool spots; fluorescein angiography showing extensive (more than 10 disk areas of nonperfusion) retinal capillary nonperfusion not only at the periphery, but also in the macular area [8].

The presence of macular ischemia (evaluated by enlargement of the foveal avascular zone on fluorescein angiography) has prognostic significance as it indicates a lower likelihood of visual recovery. A potential for conversion from nonischemic to ischemic CRVO has been reported in $12-30 \%$ of cases over a follow-up period of 3 years $[2,56]$.

While fluorescein angiography can be useful to determine the degree of vascular incompetence, spectral domain optical coherence tomography (SD-OCT) is an important tool in the management of patients with vein occlusion as it is critical and helps to quantify the amount of cystoid macular edema, and supplies additional information such as whether the accumulated fluid is located mostly within the retinal layers or in the subretinal space as well [72]. After resorption of this fluid, severe ischemia induces an accentuated reduction of thickness and atrophy of the macular area.

Final visual prognosis is dependent on the presence and integrity of the external limiting membrane and of 
the inner and outer segments of the photoreceptors (inner/outer segment interface). Hyperreflective dots on SDOCT, mainly in the outer layers, are suggestive of an inflammatory reaction, and may be a marker of disease activity [87].

In case of preocclusive disease with initial intraretinal hemorrhages and tortuosity of retinal vessels, SD-OCT may show a normal appearance. In case of impending vein occlusion, patches of increased reflectivity are present at the level of the inner plexiform layer with a shadow effect. When an ischemic component exists, a thinning of the nerve fiber layer soon becomes evident.

Good evidence exists to show that early treatment can be beneficial to treatment. This is especially important in contrast to the previous common notion of waiting at least 3 months before initiating treatment for vein occlusion $[59,86]$.

\subsubsection{Management of Nonischemic and Well-Perfused CRVO}

\subsection{Nonischemic CRVO and Good VA}

In patients with nonischemic (well-perfused) CRVO and good VA (better than 20/40), the prognosis is favorable and monitoring is possible. In this case, no immediate therapy needs to be advised, but there still is a need to screen all new patients for vascular risk factors such as hypertension, dyslipidemia and diabetes. Treatment of these underlying causes is of paramount importance to prevent complications. An investigation of other risk factors should be considered only when the clinical history suggests their presence, in the absence of other obvious etiology [23]. Local factors predisposing to or associated with CRVO, such as open-angle glaucoma, should be ruled out and treated appropriately to reduce the risk of progression to a more ischemic state $[40,42]$.

Monitoring during follow-up is aimed at identifying persistent macular edema and/or conversion to ischemic CRVO. Key elements in the clinical examination include VA assessment, biomicroscopy and OCT. Fluorescein angiography should be performed whenever there is doubt regarding progression, or to assess the degree of ischemia.

Patients should be monitored monthly for the first 3 months, and then every 2 months for the first year. During this monitoring period, patients should be instructed to return promptly whenever they notice a decrease in vision, a possible indication of macular edema, or the conversion to ischemic CRVO.

\subsection{Nonischemic CRVO and VA of 20/40 or Less}

In nonischemic CRVO, with a VA which is $20 / 40$ or less, one should search for macular edema. In case of macular edema, treatment should be initiated rather than observation.

\subsection{Management of Macular Edema in Well-Perfused CRVO}

\subsection{Laser Photocoagulation}

In the CVOS, even though grid laser photocoagulation was able to reduce macular edema, there was no statistically significant VA benefit, except for the younger patient group [88]. Thus, grid laser photocoagulation is not currently indicated.

Current treatment options include corticosteroids and antivascular endothelial growth factor (VEGF) approaches. Eyes affected by macular edema secondary to CRVO must be considered for treatment whenever VA is lower than 20/40. Indeed, a natural history of eyes with VA greater than $20 / 40$ is more often favorable [69].

\subsection{Corticosteroids Approach}

Several corticosteroids formulations exist. However, not all steroids are the same in potency and side effects. The rationale for the use of steroids to treat macular edema is related to their ability to reduce capillary permeability, and to inhibit the expression of VEGF gene and the metabolic pathway of VEGF. Therapy with corticosteroids should rely on randomized clinical trials.

\subsection{1. Dexamethasone}

Dexamethasone has been used for a long time as a potent corticosteroid that decreases inflammatory mediators implicated in macular edema. Previous data suggest fewer side effects than for other corticosteroids.

Dexamethasone is highly soluble and has a short halflife following intravitreal injection. To provide a sustained delivery of dexamethasone, a slow release, biodegradable implant (Ozurdex; Allergan) was developed, providing medication for up to 6 months at the posterior pole following implantation in the vitreous cavity. Its therapeutic effects on macular edema associated with RVO were investigated in a 6-month, randomized, controlled clinical trial (the Ozurdex GENEVA study) [59]. A prefilled, single-use applicator containing $0.7 \mathrm{mg}$ of dexamethasone in a slow-release polyglycolate-acetate implant allows the insertion of the drug. 
The study design included 2 identical, randomized, prospective, multicenter, masked, sham-controlled parallel groups. In the double-masked initial treatment phase, patients were randomly assigned (1:1:1) to receive either a $350-\mu \mathrm{g}$ or a $700-\mu \mathrm{g}$ dexamethasone implant, or to receive sham treatment (needleless applicator). In the second open-label phase (second injection), all eligible patients received a 700- $\mu$ g dexamethasone implant and were followed for 6 months using the same follow-up protocol as in the initial phase. The primary endpoint was the time to achieve a $\geq 15$-letter improvement (3 Snellen lines) in best-corrected VA (BCVA), and key secondary endpoints included BCVA over the 6-month trial period, central retinal thickness measured by OCT, and safety.

The Ozurdex GENEVA study demonstrated that the biodegradable implant containing $0.7 \mathrm{mg}$ of dexamethasone (Ozurdex) resulted in improved VA, revealing a peak effect after 2 months and a progressive decline to baseline values at 6 months. On average, patients achieved a 10 -letter gain at day 60 after implantation. VA improvement can be effectively achieved after a second injection at month 6 over a 1-year follow-up [59]. Anatomically, improvements in macular edema were documented by OCT.

The data on safety showed a low cataract rate and low rates of intraocular pressure increases. Moderately raised intraocular pressure was registered in about $15 \%$ of cases, with a peak at month 2 , but it tended to decline over the follow-up period, especially if treated with antiglaucoma drops, with the majority of patients being able to discontinue the drops by 6 months after implantation. No adverse events were related to the injection.

The study was also able to show that early treatment of macular edema was more beneficial than delayed treatment in restoring VA. A post hoc analysis suggested that eyes treated within 90 days since the onset of cystoid macular edema were more likely to improve than eyes in which the treatment was instituted after this time point. It is likely that a dexamethasone implant should be reinjected more frequently, following the individual response of each patient over the follow-up.

Ozurdex has received FDA and EU approval and is licensed in all EU countries for the treatment of adult patients with macular edema following CRVO. The results of the study suggest that the slow-release device for intraocular dexamethasone delivery could be considered a first-choice therapy for the management of macular edema in well-perfused CRVO.

Management of RVO - Consensus Document

\subsection{2. Triamcinolone Acetonide}

A triamcinolone acetonide preparation containing benzyl alcohol has been used for a number of years to treat patients off label (Kenalog ${ }^{\circledR}$; Squibb). Many small case series regarding the beneficial effects of this preparation in the treatment of macular edema associated with nonischemic CRVO have been published [16]. However, Kenalog has a number of side effects including the development of cataract and raised intraocular pressure. The presence of benzyl alcohol also leads to an increased risk of sterile endophthalmitis. Though indicated for intraarticular joint use, its ocular use is contraindicated.

The multicenter SCORE trial $[58,89]$ has confirmed the beneficial effects of intravitreal triamcinolone acetonide for the treatment of macular edema associated with nonischemic CRVO [90]. For the purpose of this study, a preservative-free triamcinolone preparation was used (Trivaris; Allergan). In the SCORE CRVO study [90], 271 participants with macular edema secondary to perfused CRVO were included. The odds of achieving the primary outcome were 5.0 times greater in the $1-\mathrm{mg}$ group than in the observation group $(\mathrm{p}=0.001)$, and 5.0 times greater in the 4-mg group than in the observation group $(\mathrm{p}=0.001)$. There was no difference identified between the 1-mg and 4-mg groups $(\mathrm{p}=0.97)$.

The 1-mg dose showed a better safety profile compared with the 4-mg dose, with lower incidence rates of raised intraocular pressure, cataract formation, progression and surgery. Although FDA approved, Trivaris is not yet available in Europe.

As a consequence, at present there is no evidence to suggest that the visual and anatomical responses seen with Trivaris in the SCORE study would be achieved with off-label intravitreous triamcinolone acetonide preparations such as Kenalog.

\subsection{Anti-VEGF Approach}

Intravitreal anti-VEGF administration of ranibizumab, bevacizumab and pegaptanib have been investigated.

\subsection{1. Ranibizumab}

Ranibizumab is a pan-VEGF blocker (Lucentis ${ }^{\circledR}$; Novartis) proved to be effective in the CRUISE trial [84]. Ranibizumab was injected monthly in 2 doses $(0.3$ and 0.5 $\mathrm{mg}$ ) for the first 6 months, producing a mean gain in VA of 12.7 and 14.9 letters, respectively, compared with sham injection at 6 months. Following the first 6 months, all patients underwent an open-label extension with an additional 6 months of follow-up with therapy pro re nata.

Ophthalmologica 2011;226:4-28 
Overall, the 12-month results suggested that the visual gain could be sustained. Moreover, earlier treatment could lead to a greater functional improvement than delayed therapy. Ranibizumab $0.5 \mathrm{mg}$ has received a license for the treatment of macular edema following RVO in the USA, and a regulatory authorization is expected within the year 2011 in the EU.

\subsection{2. Bevacizumab}

Bevacizumab is a pan-VEGF blocker (Avastin ${ }^{\circledR}$; Roche) unlicensed for intraocular use. Although there is no randomized clinical trial involving bevacizumab in RVO, many uncontrolled case series have reported that intravitreal administration can lead to a VA improvement and resolution of macular edema [91, 92]. However, because of the variation in dosing and treatment regimens among these studies, both long-term outcomes and safety data remain unclear. The drug has the advantage to be less costly, which has helped its widespread use.

\subsection{3. Pegaptanib}

Pegaptanib is a selective anti-VEGF ${ }^{165}$ blocker (Macugen ${ }^{\circledR}$; Pfizer). The first multicenter randomized study on the effect of anti-VEGF therapy in the treatment of RVO was designed to evaluate the efficacy of pegaptanib sodium. The results were reported in 2006 at the Congress of the European Vitreoretinal Society. Patients with visual loss due to macular edema secondary to CRVO were randomly assigned to sham injection, $0.3 \mathrm{mg}$ or $1 \mathrm{mg}$ of pegaptanib sodium. A phase II trial indicated that 0.3 mg intravitreal pegaptanib given every 6 weeks over a 6-month follow-up improved VA by approximately 7 letters at 6 months [93]. The best treatment regimen and response to treatment in the long run still remain unclear.

\subsection{Recommendations for Further Follow-Up}

Follow-up after the initial 6 months will depend upon whether steroid or anti-VEGF treatment was initiated for macular edema, but it will normally be required for up to 2 years in uncomplicated cases. The eyes should be monitored for conversion to ischemia and for occurrence/recurrence of macular edema. The development of disk collaterals and the resolution of macular edema should lead to discharge from close clinical supervision, but the risk of conversion remains present and should be explained to the patients.

Recurrence or persistence of macular edema, diagnosed by a decrease in VA and/or by biomicroscopic and OCT examination (and fluorescein angiography in case of any doubt), should lead to a decision of reinjection dur- ing the follow-up period. Additional laser photocoagulation could be suggested for nonresponding or partially responding patients, or for patients not complying with multiple reinjections.

\subsubsection{Management of Ischemic CRVO}

In patients with ischemic CRVO, primary evaluation should assess the presence of macular perfusion as well as the existence of neovascularization.

\subsection{Macular Perfusion}

In cases with macular edema and a still perfused macula, the same treatment as outlined above for cases of nonischemic CRVO should be initiated.

In case of a macula which is nonperfused, treatment should be initiated even if the expectation of visual improvement remains limited. Dexamethasone implants have been reported to be effective at least in a subset of patients [94].

\subsection{Peripheral Nonperfusion}

Ischemic CRVO is usually characterized by peripheral retinal nonperfusion greater than 10 disk diameters, as evaluated by fluorescein angiography examination. Development of ocular neovascularization is directly related to the extent of nonperfusion.

Cases with extensive retinal nonperfusion, or with limited compliance, may be considered for early panretinal photocoagulation (PRP) in an attempt to block the development of ocular neovascularization. In less severe cases, scatter treatment directed at the nonperfused areas may be sufficient.

In addition to an eventual treatment for macular edema, patients with ischemic CRVO without neovascularization should be followed up at least monthly, undergoing VA, biomicroscopy, OCT and fluorescein angiography (if needed). The corneal angle and iris should also be examined in an attempt to discover early neovascular tufts [95].

\subsection{Management of Neovascularization}

\subsection{Anterior Segment Neovascularization}

Whenever anterior segment neovascularization (angle and/or iris neovascularization) is identified, evidencebased medicine supports the administration of PRP. In particular, the extension of anterior segment neovascu- 
larization (which explicitly requires PRP) has been defined as any angle neovascularization and/or 2 clock hours of iris neovascularization [8].

A complete PRP can be achieved in single or multiple sessions to cover the entire retina from the periphery to the vascular arcades. PRP generally requires a minimum of 1,500-2,000 burns, or even more, of 500- $\mu \mathrm{m}$ size, with 0.1 -second applications. Laser burns should be placed 1 burn width apart with sufficient energy to produce a pale white burn in the retina. Treatment is usually placed trying to avoid areas of retinal hemorrhage. The laser application must begin with the inferior quadrants, may be completed in a few weeks, and can be repeated whenever anterior segment neovascularization fails to regress.

Even though there is no randomized clinical trial of the combined therapy, it is reasonable to administer an intravitreal anti-VEGF agent in association with PRP as it may lead to faster regression of anterior segment neovascularization [96, 97]. Limited experience has been gained regarding the treatment of anterior segment neovascularization with anti-VEGF monotherapy [98]. However, none of the available anti-VEGF agents (bevacizumab, ranibizumab and pegaptanib) currently has regulatory approval for such an indication.

\subsection{Posterior Segment Neovascularization}

Posterior segment neovascularization (retinal and/or optic disk neovascularization) can develop alone or in association with anterior segment neovascularization. However, posterior segment neovascularization can be treated with PRP, following the above-mentioned suggestions.

As stated above, combined treatment with anti-VEGF and PRP may prove useful to effectively control the growth of neovascularization. Monotherapy with intravitreal injection of anti-VEGF agents such as ranibizumab and bevacizumab can lead to a transient regression of ocular neovascularization [96, 97].

Thus, even though at present no specific randomized clinical trial has proven the efficacy of the anti-VEGF approach, it is likely that repeated injections are required to stop neovascular growth, but it is unknown whether this approach can lead to a definitive cessation of the neovascular stimulus.

Patients presenting with widespread ocular neovascularization should be treated with PRP as soon as possible. Especially in eyes with vitreous hemorrhage, the combined therapy with anti-VEGF agents may prove useful to stop the growing of ocular neovascularization, allowing at the same time the application of prompt PRP in a few sessions (if the vitreous hemorrhage is not too dense, which would then require vitrectomy and endolaser therapy).

\subsection{Neovascular Glaucoma}

In the case of established neovascular glaucoma, intravitreal bevacizumab has been shown to cause regression of iris new vessels and decrease angle obstruction. Comparative case series indicate that iris new vessels regress faster after intravitreal bevacizumab with PRP than with PRP alone. The reports also suggest that bevacizumab may reduce the need for surgical interventions and serve as a useful adjunct to filtering surgery.

\subsection{Juvenile CRVO}

Juvenile CRVO, occurring in people younger than 50 years, seems to be a different entity regarding pathogenesis and clinical course, and should be differentiated from CRVO developing after 50 years of age. In some cases, when the disease is associated with severe systemic disease, patients need to be addressed for complete systemic evaluation, and the prognosis can be guarded.

Juvenile CRVO is often of a nonischemic type, with no clearly identifiable risk factors, and sometimes related to an inflammatory pathogenesis, as shown by the detection of vitreous cells [24]. Visual prognosis is generally better in comparison with ordinary CRVO, even though possible complications include ocular neovascularization and the development of macular edema.

Some evidence exists that systemic steroids can lead to a faster resolution of the disease. Even though there is no randomized clinical trial, it is plausible that intraocular steroids, especially the intravitreal slow-release dexamethasone implant, may prove useful in the management of macular edema secondary to juvenile CRVO.

\subsubsection{Management of BRVO}

\subsubsection{Systemic Risk Factors and Classification of BRVO Subtypes}

The management of BRVO has many similarities to the management of CRVO with regard to systemic risk factors, but it presents some important differences because this type of RVO carries a lower risk of progressive worsening and conversion to ischemia and a lower risk of neovascularization. 
Thus, the management of BRVO should embrace several targets including: the identification and management of systemic risk factors (specifically hypertension, cardiovascular diseases and diabetes mellitus); a precise classification of the area of inclusion to determine major branch versus tributary branch occlusion (especially macular BRVO); an assessment of the degree of peripheral perfusion and degree of macular ischemia, and the institution of treatment according to sight-threatening complications (mainly persistent macular edema and neovascularization in some cases of extensively affected quadrants).

\subsubsection{BRVO with Perfused Periphery and Normal VA}

In case of a BRVO with a perfused periphery and normal VA, the prognosis is favorable and monitoring is possible. In this case, no therapy needs to be advised.

In the follow-up examination, one should look for significant macular edema by VA examination, biomicroscopy and OCT. If in doubt, fluorescein angiography should be performed.

Patients should be monitored monthly for the first 3 months, and then every 2 months for the first year. During this monitoring period, patients should be instructed to quickly report whenever they notice a loss of VA, which may indicate the development of macular edema.

\subsubsection{BRVO and Symptomatic VA Decline}

In cases of BRVO and symptomatic decline in VA, an assessment should be performed for the existence of macular edema. If there is macular edema seen by OCT, treatment should be considered according to the following outline.

Special attention should be paid to macular BRVO, a subtype of BRVO involving a small vein draining a sector of the macular region. Macular BRVO could have a more favorable natural course, not requiring treatment in most cases [99].

\subsection{Laser Photocoagulation}

For many years, grid laser photocoagulation has been the standard care and recommended for patients with macular edema associated with branch vein occlusion who met the BVOS eligibility criteria (VA of 20/40 or less, persistent macular edema lasting for 4 months or longer, and resorption of macular hemorrhages). This study was a multicenter, randomized, controlled clinical trial designed to address questions regarding the management of complications of branch vein occlusion $[70,71]$.

In 1993, another prospective study concluded that argon laser photocoagulation treatment in areas of ischemia should be provided only when neovascularization was seen and not otherwise, because in the latter case, the detrimental effects of laser coagulation (including scotomas in the pericentral visual field) might outweigh its beneficial ones [2].

Recently, based on the results of a new prospective, double-masked randomized trial, the SCORE study, it was recommended that grid photocoagulation should remain the treatment of choice for eyes with vision loss associated with macular edema secondary to BRVO [58, 89]. The study concluded that no difference was found in VA at 12 months in the standard care group (grid laser photocoagulation) compared with the triamcinolone groups. Moreover, rates of adverse events (particularly elevated intraocular pressure and cataract) were highest in the 4-mg triamcinolone group.

However, paracentral laser coagulation leads to paracentral visual field defects. Central VA and the paracentral visual field both contribute to the quality of vision. Since the paracentral visual field was not examined when assessing reading ability, the conclusions from the SCORE BRVO study may remain questionable, and it may be unclear whether the results also referred to quality of vision in general $[58,89]$.

Finally, if there is an extensive and large area of nonperfusion in the peripheral quadrant, particular monitoring should be advised to detect any neovascularization, and scatter laser photocoagulation could be suggested.

\subsection{Intravitreal Drugs}

\subsection{Intravitreal Steroids}

\subsection{1. Dexamethasone}

Dexamethasone has been used for a long time as a potent corticosteroid that decreases inflammatory mediators implicated in macular edema. Because of the short half-life of intravitreal injections of dexamethasone, an intravitreal dexamethasone implant (Ozurdex) was developed to deliver sustained levels of dexamethasone to the back of the eye, in a 6-month, randomized, controlled clinical trial of macular edema associated with RVO, the Ozurdex GENEVA study. A prefilled applicator singleuse, sustained-release biodegradable implant containing 
$0.7 \mathrm{mg}$ of dexamethasone (Ozurdex) has been studied in this trial.

Patients received a single masked treatment at baseline. At 6 months, all patients received a second treatment in an open-label fashion. In this, two identical, randomized, prospective, multicenter, masked, sham-controlled, parallel-group phase III clinical trials showed a statistically significant effect and rapid action, with a maximum effect at day 60 and a decrease in effect beginning at day 90 but still persistent at day 180 . The second injection was even slightly more effective than the first injection. No adverse events were related to the injection, with a very low cataract rate and very low rates of persistent intraocular pressure increase.

The primary endpoint was the time to achieve a $\geq 15$-letter (3-line) improvement in BCVA, and key secondary endpoints included BCVA over the 6-month trial period, central retinal thickness measured by OCT, and safety.

The duration of the macular edema was similar in each group, with about $15 \%$ of patients with a macular edema duration of $<3$ months, $50 \%$ with a macular edema duration between 3 and 6 months, and 30\% with a macular edema duration of $>6$ months ( $16.4 \%$ of patients: $<3$ months; $51.3 \%$ : between 3 and 6 months; $32.3 \%$ : $>6$ months). It is noteworthy to mention that the percentage of patients with macular edema for $<3$ months was only $15 \%$, in comparison with $>50 \%$ in the SCORE BRVO trial [89], 51.5-53.8\% in the BRAVO trial [85] and 51.5$61.5 \%$ in the CRUISE trial [84]. This might affect the results and add difficulties when comparing trials, since spontaneous resolution is higher among those trials in which a large number of patients have a short duration of macular edema.

The proportion of patients achieving at least a 15-letter or 10-letter improvement from baseline BCVA was significantly greater in the dexamethasone $700-\mu$ g group than in the sham group from day 30 through day 90 . The greatest response was seen at day 60 :

- $29.6 \%$ of patients in the dexamethasone $700-\mu$ g group achieved at least a 15-letter improvement from baseline as compared with $12.5 \%$ in the sham group ( $\mathrm{p}<$ $0.001)$;

- $51.9 \%$ of patients in the dexamethasone $700-\mu$ g group achieved at least a 10-letter improvement from baseline as compared with $29.4 \%$ in the sham group $(\mathrm{p}<0.001)$. At day $180,41.2 \%$ of patients in the dexamethasone 700 $\mu \mathrm{g}$ group achieved at least a 10-letter improvement from baseline as compared with $33 \%$ in the sham group ( $\mathrm{p}=$ $0.041)$.

Management of RVO - Consensus Document
The difference in mean change in BCVA from baseline between the dexamethasone $700-\mu$ group and the sham group was statistically significant at all time points for BRVO patients. Mean VA improved by 10 letters at 2 months, declined to 9 letters by month 3 , and to 7 letters by month 6 . In the control group, mean VA improved to 4-5 letters by month 2 , and stayed stable during the 6 months. The mean change from baseline in BCVA was similar following a second treatment with dexamethasone 700 or $350 \mu \mathrm{g}$. Patients who had received sham treatment in the initial treatment phase demonstrated a lower mean change from baseline in BCVA after having received open-label treatment than patients who had received dexamethasone 700 or $350 \mu \mathrm{g}$ during the initial treatment phase.

The percentage of patients in the dexamethasone groups with an intraocular pressure of $\geq 35 \mathrm{~mm} \mathrm{Hg}$ (about $2-3 \%$ of the patients at day 60), $\geq 25 \mathrm{~mm} \mathrm{Hg}$ (about $15 \%$ of the patients at day 60 ) and a change from baseline of $\geq 10 \mathrm{~mm} \mathrm{Hg}$ (about $15 \%$ of the patients at day 60) presented a peak at day 60 , but returned to baseline values by day 180 . After 12 months (2 injections of dexamethasone), only $1.2 \%$ of the patients $(\mathrm{n}=4)$ had an intraocular pressure procedure, and $0.9 \%$ of the patients $(n=3)$ had cataract surgery (for the $700-\mu \mathrm{g} / 700-\mu \mathrm{g}$ group, patients were injected 2 times). Adverse events after initial treatment, the maximum severity of which increased during the open-label extension, were reported for $2.6 \%$ of the patients (700- $\mu \mathrm{g} / 700-\mu \mathrm{g}$ group).

A more recent analysis of the GENEVA results [59] has shown that treating edema secondary to BRVO of short duration has a better effect than delaying the treatment. The percentage of reduced odds of gaining 15 letters with treatment at day 180 was $54 \%$ if the duration of the edema was 6 months, 32\% if the duration of the edema was 3 months, and $12 \%$ if the duration of the edema was 1 month.

Ozurdex has received FDA and EU approval for the 0.7-mg dexamethasone implant for the treatment of macular edema secondary to RVO.

\subsection{2. Intravitreal Triamcinolone Acetonide}

Due to its antiedematous and anti-angiogenic effects, as shown in experimental investigations and clinical studies, intravitreal triamcinolone acetonide has been used in many pilot studies on RVO. Due to the limited duration of the intraocular availability of triamcinolone, the visual improvement is limited in its duration.

Recently, the SCORE multicenter clinical trial compared the efficacy and safety of 1-mg and 4-mg doses of 
preservative-free intravitreal triamcinolone with standard care (grid photocoagulation in eyes without dense macular hemorrhage, and deferral of photocoagulation until hemorrhage clears in eyes with dense macular hemorrhage) for eyes with vision loss associated with macular edema secondary to BRVO. The drug used in this trial was prepared as a sterile, preservative-free, single-use intravitreal injection (Trivaris) with 1-mg and 4-mg doses in a volume of $0.05 \mathrm{ml}$. The SCORE trial concluded that there was no difference identified in VA at 12 months for the standard care group compared with the triamcinolone groups; however, rates of adverse events (particularly elevated intraocular pressure and cataract) were highest in the 4-mg group [58, 89]. It is possible that the VA results in the treated group were somewhat biased because of the high percentage of cataract progression in this group.

The authors inferred that grid photocoagulation as applied in the SCORE study has remained the standard care for patients with vision loss associated with macular edema secondary to BRVO who present similar characteristics to those patients in the SCORE BRVO trial.

As mentioned in the natural course section, the duration of the edema is important to be considered. In the subgroup analysis of the SCORE BRVO trial, those patients with a disease duration of $<3$ months showed a trend toward greater benefit with classical treatment. However, of those patients with a macular edema for $>3$ months, $34 \%$ showed a gain of 15 letters or more in the 4-mg group, versus $15 \%$ in the photocoagulation group. According to the authors, these figures were not statistically significant but indicated the importance of taking into account the duration of edema in data analysis and when comparing the results of different trials, which may differ in baseline characteristics. In the SCORE BRVO trial, $>50 \%$ of the patients had a macular edema for $<3$ months $[58,89]$.

\subsection{Intravitreal Anti-VEGF Drugs}

Intravitreal anti-VEGF administration has been tried with ranibizumab, bevacizumab and pegaptanib.

\subsection{1. Bevacizumab}

Since the landmark study on the intravitreal use of bevacizumab for the treatment of exudative age-related macular degeneration [100], bevacizumab has become a medication used worldwide for patients affected by various neovascular intraocular diseases including RVO [101-107].
The majority of the studies failed to clearly differentiate between the nonischemic and ischemic types of RVO. Moreover, these studies were mostly case series without a randomized control group.

\subsection{2. Pegaptanib}

The first multicenter randomized study on the effect of anti-VEGF therapy in the treatment of RVO was designed to evaluate the efficacy of pegaptanib sodium.

The results were reported at the Congress of the $\mathrm{Eu}-$ ropean Vitreoretinal Society in 2006. Patients with visual loss due to macular edema secondary to CRVO were randomly assigned to sham injection, 0.3 or $1 \mathrm{mg}$ of pegaptanib sodium. The group treated with $1 \mathrm{mg}$ pegaptanib sodium showed a higher rate of visual gain superior to 5 letters and a lower rate of loss of 15 letters or more than the control group ( $<<0.05$ and $\mathrm{p}<0.01$, respectively).

There was a difference of 13 letters in the change in VA between the control group (sham injections) and the group treated with $1 \mathrm{mg}$ pegaptanib sodium.

\subsection{3. Ranibizumab}

Ranibizumab is a pan-VEGF blocker (Lucentis) which was proved to be effective in the BRAVO trial.

The BRAVO trial was a multicenter, randomized, double-masked, sham injection-controlled phase III study of 397 patients designed to assess the safety and efficacy profile of Lucentis in macular edema secondary to BRVO.

Patients were randomized into 3 groups: standard care with grid laser treatment, intravitreal injection of $0.5 \mathrm{mg}$ ranibizumab, and both grid laser and intravitreal injection of 0.3 or $0.5 \mathrm{mg}$ ranibizumab. The patients received monthly intravitreal injections during the first 6 months, and between month 6 and month 12, evaluations were carried out to determine whether retreatment was needed. In both studies, the preliminary results at 6 months showed that the treated groups had better visual recovery than the control groups.

In the BRAVO study [85], at 6 months, $55 \%$ of the patients who received $0.3 \mathrm{mg}$ of Lucentis and $61 \%$ who received $0.5 \mathrm{mg}$ of Lucentis had their vision improved by 15 letters or more compared to $29 \%$ of patients receiving sham injections and grid laser treatment.

At 6 months, with an average of 5.7 injections in the first 6 months, the mean visual gain was 16.6 and 18.3 letters $(0.3$ and $0.5 \mathrm{mg})$, compared with 7.3 letters in the sham group. However, from months 3 to 5, a single application of rescue laser photocoagulation was also allowed in all study arms. 
From months 6 to 12, the patients were treated in an open-label fashion pro re nata. Visual benefit was maintained with an additional mean number of injections of 2.7 in the second 6 months. Patients in the sham group also showed a benefit, although the amount of visual gain did not reach that of the patients who had been treated from baseline. As stated above, more than half of the patients in the BRAVO trial had macular edema of a short duration (51.5-53.8\%).

Ranibizumab $0.5 \mathrm{mg}$ has been approved in the USA for the treatment of macular edema secondary to RVO, and has received a positive opinion from the Committee for Medicinal Products for Human Use for approval in the $\mathrm{EU}$ for the treatment of diabetic macular edema. It has not yet been approved for RVO by the EMA; however, Novartis is planning to file for the drug's approval in the EU for treating macular edema due to RVO.

\subsubsection{Management of BRVO with Peripheral Nonperfusion}

In these cases, the perfusion of the macula should be assessed. If it is perfused, treatment should be contemplated as outlined above. Laser treatment of the peripheral areas of nonperfusion can be considered if the nonperfused area is very extensive.

If the macula is not perfused, again, treatment should be contemplated as outlined above, with informed consent of patients as the prognosis can be bleak.

In cases of BRVO with peripheral neovascularization, intravitreal therapy should be initiated, followed by scatter laser aimed at the area of the occluded vein.

\section{Prevention}

Only few studies have addressed the prevention of recurrence of RVO in the same eye, or of the development of RVO in the contralateral eye. So far, none of these studies have shown any benefit. Thrombocyte aggregation inhibitors and anticoagulant drugs could not be shown to be of benefit $[108,109]$.

Available data support the concept that recurrence of RVO may be reduced by medical treatment of underlying cardiovascular risk factors.

Historically, hormone replacement therapy was contraindicated and discontinued following central vein occlusion. Currently, the decision about whether to continue hormone replacement therapy in women with RVO should be made on a case-by-case basis.

Management of RVO - Consensus Document

\section{Surgical Approaches to Treating RVO}

The focus of such surgical treatments is either the occluded retinal vein itself or the macular edema. Many surgical treatment modalities have been reported for RVO. Of the following common surgical approaches, only a few are frequently utilized:

(1) radial optic neurotomy ( $\mathrm{RON})$;

(2) chorioretinal venous anastomosis;

(3) vitrectomy with or without internal limiting membrane (ILM) peeling;

(4) injection of tissue plasminogen activator (t-PA) into the lumen of a retinal vein via retinal vein cannulation; (5) arteriovenous sheathotomy.

\subsection{Radial Optic Neurotomy}

Radial neurotomy has been suggested as a therapy for CRVO [110-113]. However, randomized prospective trials have not yet shown beneficial effects of radial neurotomy in the treatment of CRVO, so that it is unclear whether the technique should be recommended [86]. Again, in most clinical sites, this surgical technique was not introduced or has been abandoned.

Radial neurotomy was first described as a therapy for CRVO [113]. The authors hypothesized that the anatomy of the optic nerve head (ONH) and scleral outlet might play a role in the development of CRVO, and they performed surgical decompression of the vein by making a radial incision of the $\mathrm{ONH}$.

Moreover, RON was thought to induce the postoperative development of optociliary venous anastomosis or retinochoroidal shunts, leading to increased retinal venous outflow [111, 113-116]. The technique involved an incision on the nasal side of the optic nerve, radial to the nerve and parallel to the nerve fiber layer. In their pilot study of 11 patients with CRVO, VA improved in $73 \%$ of patients, with an average gain of 5 lines of vision.

These results were challenged by Hayreh [86], who suggested that RON was not a safe procedure given the close proximity of the incision site to the central retinal artery, and therefore, it carries a potential risk of cutting off the blood supply to the $\mathrm{ONH}$, and as a consequence, it may cause acute ischemia of the $\mathrm{ONH}$ and visual loss.

The controversial opinions about the effectiveness of RON warrant further investigations with larger patient populations. In a large-scale study which evaluated the outcomes of RON in 117 patients with severe CRVO, anatomic resolution was reported in $95 \%$ of patients, and

Ophthalmologica 2011;226:4-28 
visual improvement in $71 \%$ within 3 months postoperatively [117].

When RON was combined with intraocular triamcinolone injections in patients with CRVO, anatomic resolution was observed in more than $77 \%$ of patients $[118,119]$.

Improvements in VA after RON have been confirmed by several other reports $[114,119]$, although none as encouraging as those reported in studies that added intraocular triamcinolone. Several studies found a resolution of macular edema that was not accompanied by an improvement in VA in all eyes following RON $[120,121]$.

RON has been reported to cause various visual field defects. One study reported visual field defects in $83.8 \%$ of 107 cases [114]. Another study detected temporal wedge-shaped visual field defects in $88 \%$ of patients, all of which were tolerated by the patients [122].

Although RON has been considered relatively safe by most authors, the possibility of serious complications should not be overlooked. RON has been associated with a potential risk of laceration of the central retinal artery or central retinal vein, optic nerve fiber damage with visual field loss, globe perforation, retinal detachment, choroidal neovascularization at the neurotomy site, and anterior segment neovascularization $[110,113,120]$. The PACORES (Pan-American Collaborative Retina Study) Group evaluated the complications after RON for CRVO [110]. Complications occurred in $71.2 \%$ of cases, including cataract (23.2\%), vitreous hemorrhage (20.5\%), persistent macular edema (20.5\%), neovascular glaucoma (9.5\%), anterior segment neovascularization (6.8\%), retinal detachment (4.1\%) as well as phthisis bulbi, choroidovitreal neovascularization, central retinal artery perforation and optic nerve atrophy (1.3\% each).

Careful patient selection may provide better results after RON. Patients with pronounced peripapillary swelling at baseline and with an onset of CRVO of $<90$ days were reported to be more likely to benefit from RON [114]. As a result, the benefits of RON appear to be controversial and its efficacy remains to be proven in prospective randomized clinical studies. In the meantime, many centers abandoned the procedure, while others still perform it in selected cases.

\subsection{Chorioretinal Venous Anastomosis}

Chorioretinal venous anastomosis, in which a shunt is created between a retinal vein and the choroid, aims to bypass the occluded vein via an alternative route, to improve retinal outflow and to relieve the venous obstruction
[123-125]. It can be induced by means of laser $[113,123]$ or by surgery [115].

Laser-induced chorioretinal venous anastomosis involves producing an intense focal laser burn of the retina at the edge of a chosen segment of vein by using a $50-\mu \mathrm{m}$ spot size, 0.1-second duration and special power level of 1-4 W. A successful anastomosis formation was first reported in $33 \%$ of eyes with variable degrees of recovery of visual function [123]. However, this treatment was frequently associated with serious complications including posterior vitreous detachment, choroidal or vitreous hemorrhages, preretinal fibrosis, choroidal neovascularization, segmental retinal ischemia and retinal detachment $[113,123,125]$.

Surgically induced chorioretinal venous anastomosis has been described by several authors [124, 126-128]. They used different techniques to accomplish the anastomosis. One team performed standard vitrectomy and Mersilene suture insertion beneath the retina adjacent to the major retinal veins and reported visual improvement in $60 \%$ of eyes with ischemic CRVO [124].

Another surgical technique included a vitrectomy and posterior hyaloid detachment and the creation of a chorioretinal venous anastomosis by using an erbium:YAG laser [126]. Still another technique consisted of pars plana vitrectomy (PPV) with slit-like incisions through Bruch's membrane adjacent to the partially cut major retinal veins in each quadrant. Mersilene sutures were inserted into the incised sites to induce a chorioretinal venous shunt. Visual improvement was reported in $80 \%$ of 10 patients. However, $30 \%$ of the patients experienced complications with this procedure, including retinal detachment, vitreous hemorrhage and cataract [127].

A successful chorioretinal venous anastomosis was achieved in $71 \%$ of patients with CRVO by cutting off the affected retinal vein by means of vitrectomy and making a small incision at both sides of the vein interruption through the full thickness of the retina, retinal pigment epithelium and Bruch's membrane. The authors proposed that complete interruption of the vein allowed it to connect to another venous route more easily [128].

Although performing a surgically induced chorioretinal venous anastomosis does not lead to reperfusion of the areas with capillary nonperfusion, it is thought to reduce the ischemia of parafoveal and perifoveal areas, leading to VA improvement resulting from the improved venous outflow and reduced macular edema.

Many authors consider that these procedures for chorioretinal venous anastomosis are still to be classified as experimental, with a potential to cause serious side effects. 


\subsection{Vitrectomy with or without ILM Peeling}

PPV with ILM peeling has been suggested as being beneficial for the rapid resolution of retinal damage and macular edema in patients with CRVO [129-131]. However, the exact mechanism which leads to edema resolution still remains unclear. Decreased retinal thickness and increased VA were observed in more than $70 \%$ of cases after the operation in cases of macular edema caused by CRVO or BRVO $[130,131]$. These effects persisted for up to 5 years [132].

Peeling of the ILM may be reserved for clinical situations in which other modalities of treatment, namely the intravitreal injection of antiedematous (steroids) or antiVEGF drugs, have failed to achieve a satisfactory improvement in vision, and in which the blood perfusion of the macula physiologically allows an increase in VA $[112,131$, 133-141].

Comparatively successful results have also been reported for vitrectomy without ILM peeling. Vitrectomy itself can provide resolution of macular edema by removing VEGF and other cytokines within the vitreous cavity and by enhancing oxygen transport to the hypoxic retina $[142,143]$. A statistically significant improvement in patients after vitrectomy with gas/air tamponade for macular edema caused by BRVO was reported [133, 144, 145]. However, several other authors did not confirm PPV benefits for eyes with CRVO [146].

Vitrectomy showed an initial positive effect by the resolution of macular edema, but no beneficial effect in the long term [146], and it was hypothesized that vitrectomy and ILM peeling might be beneficial due to the reduction of intraretinal edema, but that these procedures failed to address the underlying pathophysiological mechanisms such as growth factor expression or altered fluid dynamics.

\subsection{Direct Injection of t-PA via Retinal Vein Cannulation}

The unsatisfactory results with systemic and intravitreal injections [147] promoted investigations of alternative routes of t-PA administration directly to the affected retinal vein [147]. The surgical techniques included PPV with posterior hyaloid removal, followed by cannulation of a peripapillary retinal vein branch and injection of a bolus of $200 \mu \mathrm{g} / \mathrm{ml} \mathrm{t}$-PA toward the $\mathrm{ONH}$.

This technique provided several advantages over other methods of t-PA delivery: (1) t-PA was delivered to pre- cisely where it was required to cause rapid lysis of the thrombus; (2) direct visualization of the drug reaching the site of thrombus was possible; (3) administration of a very small dose could provide a sufficient concentration near the thrombus, and (4) depending on its flow rate, the injection could cause a flushing effect, dislodge the thrombus and allow the dilation of the central retinal vein. Visual improvement was observed in $54 \%$ of 28 eyes with CRVO, by using this technique. In another study, a disappointing visual outcome and high complication rates have been observed after performing this surgical technique [148].

Direct injection of t-PA via retinal vein cannulation is a feasible procedure; however, it can lead to serious ocular complications including vitreous hemorrhage, retinal tear formation, retinal detachment, neovascular glaucoma, endophthalmitis and phthisis bulbi. Prospective randomized data are missing.

\subsection{Arteriovenous Sheathotomy}

In 1988, Osterloh and Charles [149] introduced a new approach involving dissection of the common adventitial sheath at the level of the arteriovenous blockage site (AVBS) in patients with BRVO and reported an improved visual outcome. The surgical procedure included PPV with posterior hyaloid detachment. The AVBS was located and a sharp pick was used to make a partialthickness inner retinotomy proximal to the AVBS. A blunt pick was then used to continue the incision parallel to and under the arteriole in a side-to-side fashion through the adventitial sheath. The ILM was not removed. The endpoint of surgery was elevation and separation of the arteriole from the underlying venule confirmed by using a subretinal spatula. More recently, a bimanual technique of arteriovenous sheathotomy followed by intravitreal recombinant t-PA led to favorable results [112].

Until now, most studies of arteriovenous sheathotomy have been poorly designed and have failed to show a convincing improvement in outcomes of BRVO that would justify the risks of the surgical procedure [141, 150]. In a study comparing the functional and anatomical outcomes of arteriovenous sheathotomy and intravitreal triamcinolone acetonide injection in the treatment of macular edema associated with BRVO, the patients showed similar functional and anatomical outcomes 6 months later. These outcomes suggested that when the cost and risks of vitreoretinal surgery are considered, intravitreal 


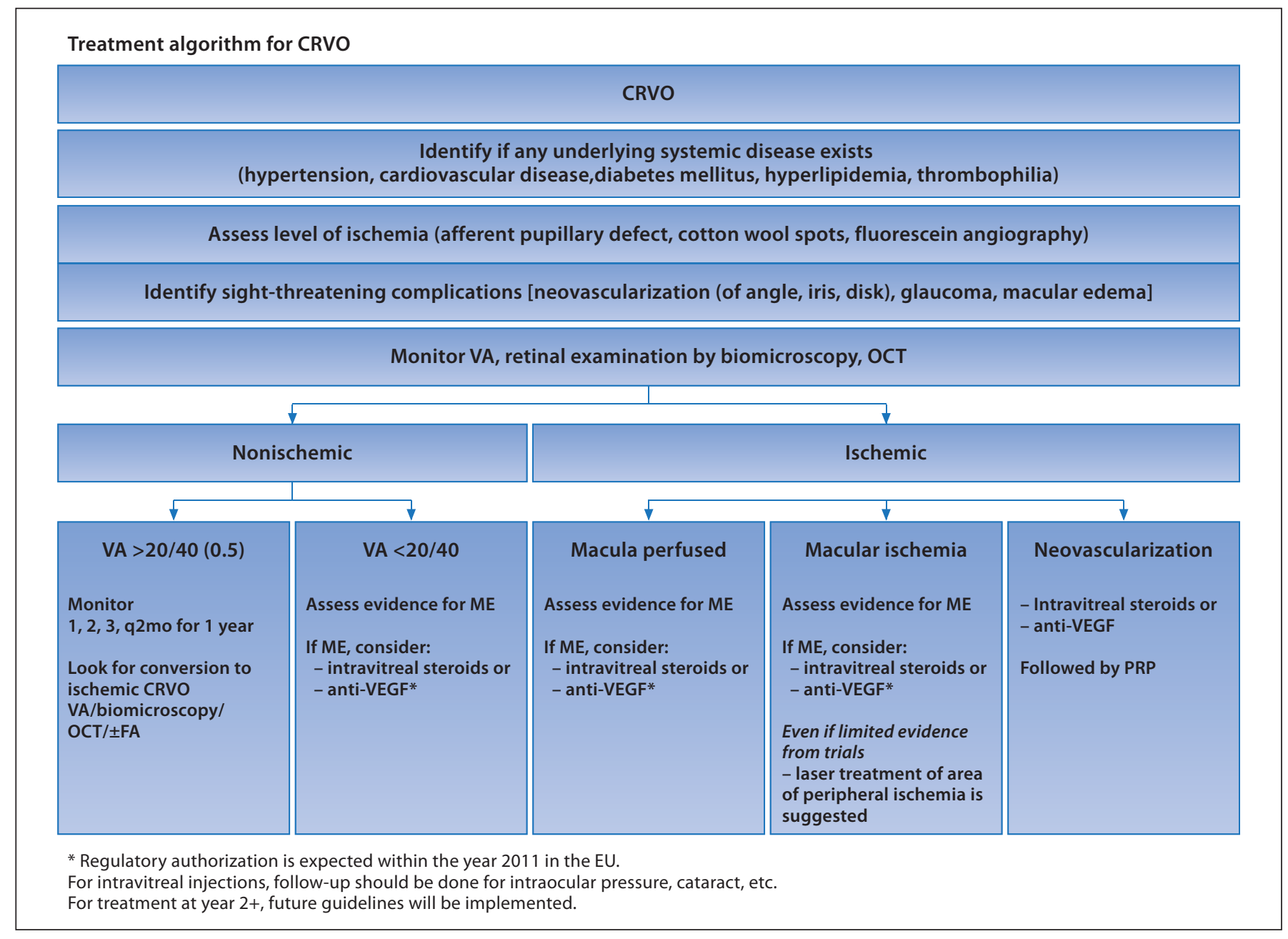

Fig. 3. Treatment algorithm for CRVO. ME = Macular edema; FA = fluorescein angiography.

triamcinolone acetonide treatment may be a better option [151].

A recent review has presented the evidence for arteriovenous sheathotomy for this condition and recommended that this procedure be done only as part of a research study [152].

Summarizing all surgical options, it seems that PPV may be beneficial in selected cases.

\section{Burden of Disease due to RVO}

It is currently estimated from pooled data from 15 population studies that there are about 520 new cases of RVO per million population [13], of which 442 are BRVO cases and 80 CRVO cases. However, only 200-260 per million will require treatment as some patients with RVO retain good vision and do not require any treatment $[8$, $56,69]$. BRVO occurs 2-3 times as often as CRVO.

\section{Strategy for Treatment of RVO}

The randomized controlled trials provided a lot of precise information for the treatment of RVO. This document aims to give guidelines on how to tailor treatment to the individual patient (fig. 3, 4).

An important learning experience from the recent trials is that duration of disease is important to outcome. Early treatment has been shown to be beneficial to the patients. Still, treatment can be beneficial also in late disease stages. 
Identify contributing factors - hypertension, cardiovascular disease, diabetes mellitus

Identify location of occlusion

Assess extent of peripheral and macular ischemia (refer to fluorescein angiography)

Identify sight-threatening complications like macular edema, neovascularization (of disk, retina, iris, angle)

\begin{tabular}{|c|c|c|c|c|}
\hline \multicolumn{5}{|c|}{ Follow BCVA, fundus biomicroscopy, ОСТ } \\
\hline \multicolumn{2}{|c|}{$\sqrt{5}$} & \multicolumn{3}{|c|}{$\frac{1}{v}$} \\
\hline \multicolumn{2}{|c|}{ Periphery perfused } & \multicolumn{3}{|c|}{ Periphery not perfused } \\
\hline 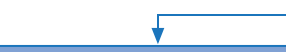 & $\nabla$ & 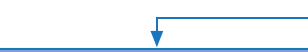 & $\downarrow$ & 7 \\
\hline VA normal & Symptomatic VA $\downarrow$ & Macula perfused & Macular ischemia & Neovascularization \\
\hline $\begin{array}{l}\text { Monitor } \\
\text { 1, 2, 3, q2mo for } 1 \text { year } \\
\text { Monitor for edema } \\
\text { VA/biomicroscopy/ } \\
\text { OCT/ } \pm \text { FA }\end{array}$ & $\begin{array}{l}\text { Assess evidence for ME } \\
\text { If ME, consider (may be } \\
\text { prior to } 3 \text { months): } \\
\text { - intravitreal steroids or } \\
\text { - anti-VEGF* } \\
\text { - laser still remains an } \\
\text { alternative if there is } \\
\text { inadequate respons } \\
\text { (during follow-up) }\end{array}$ & $\begin{array}{l}\text { Assess evidence for ME } \\
\text { If ME, consider: } \\
\text { - intravitreal steroids or } \\
\text { - anti-VEGF* } \\
\text { - consider laser } \\
\text { treatment of area of } \\
\text { peripheral ischemia }\end{array}$ & $\begin{array}{l}\text { Assess evidence for ME } \\
\text { If ME, consider (may be } \\
\text { prior to } 3 \text { months): } \\
\text { - intravitreal steroids or } \\
\text { - anti-VEGF* } \\
\text { Even if limited evidence } \\
\text { from trials } \\
\text { - laser treatment of area } \\
\text { of peripheral ischemia } \\
\text { is suggested }\end{array}$ & $\begin{array}{l}\text { Scatter laser treatment } \\
\text { of the area of ischemia } \\
\text { Consider } \\
\text { - intravitreal steroids or } \\
\text { - anti-VEGF* } \\
\text { Even if limited evidence } \\
\text { from trials }\end{array}$ \\
\hline
\end{tabular}

* Regulatory authorization is expected within the year 2011 in the EU.

** If persistent edema despite several injections of anti-VEGF or steroids.

For intravitreal injections, follow-up should be done for intraocular pressure, cataract, etc.

For treatment at year $2+$, future guidelines will be implemented.

Fig. 4. Treatment algorithm for BRVO. $\mathrm{ME}=$ Macular edema; $\mathrm{FA}=$ fluorescein angiography.

\section{$10.1 B R V O$}

A patient with BRVO should first be evaluated for known risk factors. The general physician must be notified of the occurrence of the retinal vascular occlusion and the need for diagnosis and control of arteriosclerotic risk factors. Contributing factors such as hypertension, cardiovascular disease and diabetes mellitus should be identified and treated if needed. The patient is examined by VA assessment, biomicroscopy, intraocular pressure measurement and OCT. Fluorescein angiography should be considered to identify the location of occlusion and areas of nonperfusion. The extent of peripheral and macular ischemia according to fluorescein angiography should be evaluated. The existence of macular edema and/or neovascularization (of the disk, retina, iris and angle) should be determined.

When the periphery is perfused, even if VA is $20 / 20$, monthly observation is warranted at least during the first 3 months by using VA assessment, biomicroscopy, OCT and sometimes fluorescein angiography. In stable situations, the follow-up can be performed every 3 months. 
In case of a decrease in VA during follow-up, the existence of macular edema should be assessed. If there is macular edema, treatment is recommended. First-line treatment may be with an approved drug, by single implantation of a slow-release steroid device, and consideration of re-treatment according to follow-up or, alternatively, with monthly injections of an anti-VEGF drug for 3-6 months, depending on the existence or resolution of macular edema. However, anti-VEGF has not yet been approved for this indication. Laser treatment of the thickened area still remains an alternative if there is inadequate response during follow-up.

When the periphery is not perfused, if there is macular edema, treatment is recommended. First-line treatment may be with an approved drug, by single implantation of a slow-release steroid device, and consideration of retreatment according to follow-up or, alternatively, with monthly injections of an anti-VEGF drug for 3-6 months, depending on the existence or resolution of macular edema. However, anti-VEGF has not yet been approved for this indication. Laser treatment of the thickened area still remains an alternative if there is inadequate response during follow-up. Laser treatment can be considered for the peripheral ischemic area. It should be remembered that in case of macular ischemia, the prognosis is guarded for VA recovery, even if the edema resolves.

At any time point during follow-up, the development of neovascularization should prompt the performance of scatter laser treatment of the area of ischemia. Intravitreal steroids or anti-VEGF can be considered as adjunctive treatment, even though there is limited evidence from the trials available.

\subsection{CRVO}

A patient with CRVO should first be evaluated for known risk factors. The general physician must be notified of the occurrence of the retinal vascular occlusion and the need for diagnosis and control of arteriosclerotic risk factors. Contributing factors such as hypertension, cardiovascular disease, diabetes mellitus, hyperlipidemia and thrombophilia should be identified and treated if needed. The patient is examined by VA assessment, biomicroscopy, intraocular pressure measurement and OCT. Fluorescein angiography should be considered to evaluate the extent of nonperfusion. The extent of peripheral and macular ischemia according to fluorescein angiography should be evaluated. The existence of macular edema and/or neovascularization (angle, iris, retina and disk) should be determined. The differentiation between perfused and nonperfused CRVO should be made according to areas of nonperfusion on fluorescein angiography.

If VA is $20 / 40$ or better, monthly observation is warranted at least during the first 3 months by using VA assessment, biomicroscopy, OCT and sometimes fluorescein angiography. In stable situations, the follow-up can be performed every 2 months for at least 1 year.

In the case of a decrease in VA to less than 20/40 during follow-up, the existence of macular edema should be assessed. If there is macular edema, treatment is recommended. First-line treatment may be with an approved drug, by single implantation of a slow-release steroid device, and consideration of re-treatment according to follow-up or, alternatively, with monthly injections of an anti-VEGF drug for 3-6 months, depending on the existence or resolution of macular edema. However, antiVEGF has not yet been approved for this indication.

In nonperfused CRVO, if there is macular edema, treatment is still recommended, but the prognosis is guarded. First-line treatment may be with an approved drug, by single implantation of a slow-release steroid device, and consideration of re-treatment according to follow-up or, alternatively, with monthly injections of an anti-VEGF drug for 3-6 months, depending on the existence or resolution of macular edema. However, anti-VEGF has not yet been approved for this indication. It should be remembered that in case of macular ischemia, the prognosis is guarded for VA recovery, even if the edema resolves.

At any time point during the follow-up, the development of neovascularization should prompt the performance of scatter laser treatment of the area of ischemia. Intravitreal steroids or anti-VEGF can be considered as adjunctive treatment, even though there is limited evidence from the trials available.

\section{Acknowledgment}

The Royal College of Ophthalmologists' Interim Guidelines for Management of Retinal Vein Occlusion (December 2010) were consulted during the development of these European guidelines. 


\section{References}

1 Hayreh SS: Occlusion of the central retinal vessels. Br J Ophthalmol 1965;49:626-645.

$\checkmark 2$ Hayreh SS, Rojas P, Podhajsky P, Montague P, Woolson RF: Ocular neovascularization with retinal vascular occlusion. 3 . Incidence of ocular neovascularization with retinal vein occlusion. Ophthalmology 1983;90: 488-506.

-3 Hayreh SS, Klugman MR, Beri M, Kimura AE, Podhajsky P: Differentiation of ischemic from non-ischemic central retinal vein occlusion during the early acute phase. Graefes Arch Clin Exp Ophthalmol 1990;228:201217.

$\checkmark 4$ Hayreh SS: Retinal vein occlusion. Indian J Ophthalmol 1994;42:109-132.

5 Coscas G, Dhermy P: Occlusions veineuses rétiniennes. Paris, Masson, 1978, pp 283-346.

6 Coscas G, Gaudric A: Natural course of nonaphakic cystoid macular edema. Surv Ophthalmol 1984;28(suppl):471-484.

$\checkmark 7$ Central Vein Occlusion Study Group: Baseline and early natural history report: the Central Vein Occlusion Study. Arch Ophthalmol 1993;111:1087-1095.

$\checkmark 8$ Central Vein Occlusion Study Group: A randomized clinical trial of early panretinal photocoagulation for ischemic central vein occlusion: the Central Vein Occlusion Study Group N Report. Ophthalmology 1995;102: 1434-1444.

-9 Frangieh GT, Green WR, Barraquer-Somers E, Finkelstein D: Histopathologic study of nine branch retinal vein occlusions. Arch Ophthalmol 1982;100:1132-1140.

10 Duker JS, Brown GC: Anterior location of the crossing artery in branch retinal vein obstruction. Arch Ophthalmol 1989;107:9981000 .

-11 Zhao J, Sastry SM, Sperduto RD, Chew EY, Remaley NA: Arteriovenous crossing patterns in branch retinal vein occlusion. Ophthalmology 1993;100:423-428.

$\checkmark 12$ Christoffersen NL, Larsen M: Pathophysiology and hemodynamics of branch retinal vein occlusion. Ophthalmology 1999;106: 2054-2062.

13 Rogers S, McIntosh RL, Cheung N, Lim L, Wang JJ, Mitchell P, Kowalski JW, Nguyen $\mathrm{H}$, Wong TY, International Eye Disease Consortium: The prevalence of retinal vein occlusion: pooled data from population studies from the United States, Europe, Asia, and Australia. Ophthalmology 2010;117:313319.

-14 Green WR, Chan CC, Hutchins GM, Terry JM: Central retinal vein occlusion: a prospective histopathologic study of 29 eyes in 28 cases. Trans Am Ophthalmol Soc 1981;79: 371-422.

15 Green WR: Retina; in Spencer WH (ed): Ophthalmic Pathology. An Atlas and Textbook, ed 3. Philadelphia, WB Saunders, 1985, p 589.
6 Jonas J, Paques M, Monés J, Glacet-Bernard A, Coscas G: Retinal vein occlusions. Dev Ophthalmol 2010;47:111-135.

17 Haymore JG, Mejico LJ: Retinal vascular occlusion syndromes. Int Ophthalmol Clin 2009;49:63-79.

18 Hayreh SS, Zimmerman M, Podhajsky P: Incidence of various types of retinal vein occlusion and their recurrence and demographic characteristics. Am J Ophthalmol 1994;117: 429-441.

19 Janssen MC, den Heijer M, Cruysberg JR, Wollersheim H, Bredie SJ: Retinal vein occlusion: a form of venous thrombosis or a complication of atherosclerosis? A metaanalysis of thrombophilic factors. Thromb Haemost 2005;93:1021-1026.

20 Williamson TH: Central retinal vein occlusion: what's the story? Br J Ophthalmol 1977; 81:698-704.

-21 Hayreh SS, Zimmerman B, McCarthy MJ, Podhajsky P: Systemic diseases associated with various types of retinal vein occlusion. Am J Ophthalmol 2001;131:61-77.

22 Recchia FM, Brown GC: Systemic disorders associated with retinal vascular occlusion. Curr Opin Ophthalmol 2000;11:462-467.

23 Yau JW, Lee P, Wong TY, Best J, Jenkins A: Retinal vein occlusion: an approach to diag nosis, systemic risk factors and management. Intern Med J 2008;38:904-910.

24 Dodson PM, Kritzinger EE: Underlying medical conditions in young patients and ethnic differences in retinal vein occlusion. Trans Ophthalmol Soc UK 1985; 104:114119.

25 Dodson PM, Kritzinger EE: Medical cardiovascular treatment trials: relevant to medical ophthalmology in 1997? Eye (Lond) 1997; 11(pt 1):3-11.

26 Eye Disease Case-Control Study Group: Risk factors for central retinal vein occlusion. Arch Ophthalmol 1996;114:545-554.

27 di Capua M, Coppola A, Albisinni R, Tufano A, Guida A, di Minno MN, Cirillo F, Loffredo $\mathrm{M}$, Cerbone AM: Cardiovascular risk factors and outcome in patients with retinal vein occlusion. J Thromb Thrombolysis 2010;30:16-22.

28 Dodson PM, Galton DJ, Hamilton AM, Blach RK: Retinal vein occlusion and the prevalence of lipoprotein abnormalities. Br J Ophthalmol 1982;66:161-164.

-29 Eye Disease Case-Control Study Group: Risk factors for branch retinal vein occlusion. Am J Ophthalmol 1993;116:286-296.

30 Dodson PM, Kritzinger EE, Clough CG: Diabetes mellitus and retinal vein occlusion in patients of Asian, West Indian and White European origin. Eye (Lond) 1992;6:66-68.

31 Lim LL, Cheung N, Wang JJ, Islam FM, Mitchell P, Saw SM, Aung T, Wong TY: Prevalence and risk factors of retinal vein occlusion in an Asian population. Br J Ophthalmol 2008;92:1316-1319.
32 O'Mahoney PR, Wong DT, Ray JG: Retinal vein occlusion and traditional risk factors for atherosclerosis. Arch Ophthalmol 2008;126: 692-699.

33 Prisco D, Marcucci R, Bertini L, Gori AM: Cardiovascular and thrombophilic risk factors for central retinal vein occlusion. Eur J Intern Med 2002;13:163-169.

34 Salaun N, Delyfer MN, Rougier MB, Korobelnik JF: Evaluation du bilan étiologique des occlusions veineuses rétiniennes du sujet âgé de moins de 60 ans. J Fr Ophthalmol 2007;20:918-923.

35 Shrestha RK, Shrestha JK, Koirala S, Shah DN: Association of systemic diseases with retinal vein occlusive disease. JNMA J Nepal Med Assoc 2006;45:244-248.

36 Sodi A, Giambene B, Marcucci R, Sofi F, Fedi S, Abbate R, Prisco D, Menchini U: Atherosclerotic and thrombophilic risk factors in patients with ischemic central retinal vein occlusion. Retina 2010, E-pub ahead of print.

37 Wang S, Xu L, Jonas JB, Wong TY, Cui T, Li Y, Wang YX, You QS, Yang H, Sun C: Major eye diseases and risk factors associated with systemic hypertension in an adult Chinese population: the Beijing Eye Study. Ophthalmology 2009;116:2373-2380.

38 Yasuda M, Kiyohara Y, Arakawa S, Hata Y, Yonemoto K, Doi Y, Iida M, Ishibashi T: Prevalence and systemic risk factors for retinal vein occlusion in a general Japanese population: the Hisayama study. Invest Ophthalmol Vis Sci 2010;51:3205-3209.

$>39$ Elman MJ, Bhatt AK, Quinlan PM, Enger C: The risk for systemic vascular diseases and mortality in patients with central retinal vein occlusion. Ophthalmology 1990;97:1543-1548.

40 Mitchell P, Smith W, Chang A: Prevalence and associations of retinal vein occlusion in Australia: the Blue Mountains Eye Study. Arch Ophthalmol 1996;114:1243-1247.

$\checkmark 4$ Rath EZ, Frank RN, Shin DH, Kim C: Risk factors for retinal vein occlusions: a case-control study. Ophthalmology 1992;99:509-514.

42 Hirota A, Mishima HK, Kiuchi Y: Incidence of retinal vein occlusion at the Glaucoma Clinic of Hiroshima University. Ophthalmologica 1997;211:288-291.

43 Sofi F, Marcucci R, Fedi S, Giambene B, Sodi A, Menchini U, Gensini GF, Abbate R, Prisco D: High lipoprotein(a) levels are associated with an increased risk of retinal vein occlusion. Atherosclerosis 2010;210:278-281.

44 Stojakovic T, Scharnagl H, März W, Winkelmann BR, Boehm BO, Schmut O: Low density lipoprotein triglycerides and lipoprotein(a) are risk factors for retinal vascular occlusion. Clin Chim Acta 2007;382:77-81.

-45 Turello M, Pasca S, Daminato R, dello Russo P, Giacomello R, Venturelli U, Barillari G: Retinal vein occlusion: evaluation of 'classic' and 'emerging' risk factors and treatment. J Thromb Thrombolysis 2010; 29:459-464. 
-46 Rehak M, Krcova V, Slavik L, Fric E, Langova K, Ulehlova J, Rehak J: The role of thrombophilia in patients with retinal vein occlusion and no systemic risk factors. Can J Ophthalmol 2010;45:171-175.

47 Kuhli-Hattenbach C, Scharrer I, Lüchtenberg M, Hattenbach LO: Coagulation disorders and the risk of retinal vein occlusion. Thromb Haemost 2010;103:299-305.

-48 Lahey JM, Tunç M, Kearney J, Modlinski B, Koo H, Johnson RN, Tanaka S: Laboratory evaluation of hypercoagulable states in patients with central retinal vein occlusion who are less than 56 years of age. Ophthalmology 2002;109:126-131.

-49 Larsson J, Hillarp A, Ólafsdóttir E, Bauer B: Activated protein $\mathrm{C}$ resistance and anticoagulant proteins in young adults with central retinal vein occlusion. Acta Ophthalmol Scand 1999;77:634-637.

-50 Fegan CD: Central retinal vein occlusion and thrombophilia. Eye (Lond) 2002;16:98-106.

-51 Bertram B, Remky A, Arend O, Wolf S, Reim M: Protein C, protein S, and antithrombin III in acute ocular occlusive diseases. Ger J Ophthalmol 1995;4:332-335.

-52 Kirwan JF, Tsaloumas MD, Vinall H, Prior P, Kritzinger EE, Dodson PM: Sex hormone preparations and retinal vein occlusion. Eye (Lond) 1997;11:53-56.

-53 Ciardella AP, Yannuzzi LA, Freund KB, DiMichele D, Nejat M, de Rosa JT, Daly JR, Sisco L: Factor V Leiden, activated protein C resistance, and retinal vein occlusion. Retina 1998;18:308-315.

54 Cruciani F, Moramarco A, Curto T, Labate A, Recupero V, Conti L, Gandolfo GM, Balacco Gabrieli C: MTHFR C677T mutation, factor II G20210A mutation and factor V Leiden as risk factors for youth retinal vein occlusion. Clin Ter 2003;154:299-303.

55 Glacet-Bernard A, les Jardins GL, Lasry S, Coscas G, Soubrane G, Souied E, Housset B: Obstructive sleep apnea among patients with retinal vein occlusion. Arch Ophthalmol 2010;128:1533-1538.

-56 Central Retinal Vein Occlusion Study Group: Natural history and clinical management of central retinal vein occlusion. Arch Ophthalmol 1997;115:486-491.

- 57 McIntosh RL, Rogers SL, Lim L, Cheung N, Wang JJ, Mitchell P, Kowalski JW, Nguyen HP, Wong TY: Natural history of central retinal vein occlusion: an evidence-based systematic review. Ophthalmology 2010;117: 1094-1123e15.

- 58 Scott IU, VanVeldhuisen PC, Oden NL, Ip MS, Blodi BA, Jumper JM, Figueroa M, SCORE Study Investigator Group: SCORE Study report 1: baseline associations between central retinal thickness and visual acuity in patients with retinal vein occlusion. Ophthalmology 2009; 116:504512.

- 59 Haller JA, Bandello F, Belfort R Jr, Blumenkranz MS, Gillies M, Heier J, Loewenstein A, Yoon YH, Jacques ML, Jiao J, Li XY, Whitcup
SM: OZURDEX GENEVA Study Group: randomized, sham-controlled trial of dexamethasone intravitreal implant in patients with macular edema due to retinal vein occlusion. Ophthalmology 2010;117:11341146.

60 Giuffre G, Randazzo-Papa G, Palumbo C: Central retinal vein occlusion in young people. Doc Ophthalmol 1992;80:127-132.

61 Hansen LL, Wiek J, Schade M, Müller-Stolzenburg N, Wiederholt M: Effect and compatibility of isovolaemic haemodilution in the treatment of ischaemic and nonischaemic central retinal vein occlusion. Ophthalmologica 1989;199:90-99.

62 Ramezani A, Entezari M, Moradian S, Tabatabaei $\mathrm{H}$, Kadkhodaei S: Intravitreal triamcinolone for acute central retinal vein occlusion: a randomized clinical trial. Graefes Arch Clin Exp Ophthlamol 2006;244:1601-1606.

63 Tewari HK, Lemtor MT, Azad RV, Verma L: Argon laser photocoagulation in acute central retinal vein occlusion. Afro-Asian Ophthalmol 1995;13:88-91.

64 Cugati S, Wang JJ, Rochtchina E, Mitchell P: Ten-year incidence of retinal vein occlusion in an older population: the Blue Mountains Eye Study. Arch Ophthalmol 2006;124:726732.

65 Fong ACO, Shatz H: Central retinal vein occlusion in young adults. Surv Ophthalmol 1993;37:393-417.

66 Orth DH, Patz A: Retinal branch vein occlusion. Surv Ophthalmol 1978;22:357-376.

67 Walters RF, Spalton DJ: Central retinal vein occlusion in people aged 40 years or less: a review of 17 patients. Br J Ophthalmol 1990; 74:30-35.

68 Chen HC, Wiek J, Gupta A, Luckie A, Kohner EM: Effect of isovolaemic haemodilution on visual outcome in branch retinal vein occlusion. Br J Ophthalmol 1998;82:162-167.

69 Rogers SL, McIntosh RL, Lim L, Mitchell P, Cheung N, Kowalski JW, Nguyen HP, Wang JJ, Wong TY: Natural history of branch retinal vein occlusion: an evidence-based systematic review. Ophthalmology 2010;117: 1094-1101e5.

70 Branch Vein Occlusion Study Group: Argon laser photocoagulation for macular edema in branch vein occlusion. Am J Ophthalmol 1984;98:271-282.

71 Branch Vein Occlusion Study Group: Argon laser scatter photocoagulation for prevention of neovascularization and vitreous hemorrhage in branch vein occlusion: a randomized clinical trial. Arch Ophthalmol 1986;104:34-41.

72 Shroff D, Mehta DK, Arora R, Narula R, Chauhan D: Natural history of macular status in recent-onset branch retinal vein occlusion: an optical coherence tomography study. Int Ophthalmol 2008;28:261-268.

73 Clemett RS, Kohner EM, Hamilton AM: The visual prognosis in retinal branch vein occlusion. Trans Ophthalmol Soc UK 1973;93: 523-535.
74 Michels RG, Gass JD: The natural course of retinal branch vein obstruction. Trans Am Acad Ophthalmol Otolaryngol 1974;78:166177.

75 Shilling JS, Kohner EM: New vessel formation in retinal branch vein occlusion. $\mathrm{Br} \mathrm{J}$ Ophthalmol 1976;60:810-815

76 Shilling JS, Jones CA: Retinal branch vein occlusion: a study of argon laser photocoagulation in the treatment of macular oedema. Br J Ophthalmol 1984;68:196-198.

-77 Murakami T, Takagi H, Ohashi H, Kita M, Nishiwaki $\mathrm{H}$, Miyamoto K, Watanabe D, Sakamoto A, Yamaike N, Yoshimura N: Role of posterior vitreous detachment induced by intravitreal tissue plasminogen activator in macular edema with central retinal vein occlusion. Retina 2007:27:1031-1037.

78 Royal College of Ophthalmologists: Interim guidelines for management of retinal vein occlusion: December 2010. 2010. http:// www.rcophth.ac.uk

79 Hansen LL, Wiek J, Wiederholt M: A randomised prospective study of treatment of non-ischaemic central retinal vein occlusion by isovolaemic haemodilution. Br J Ophthalmol 1989;73:895-899.

- 80 Wolf S, Arend O, Bertram B, Remky A, Schulte K, Wald KJ, Reim M: Hemodilution therapy in central retinal vein occlusion: one-year results of a prospective randomized study. Graefes Arch Clin Exp Ophthalmol 1994;232:33-39.

-81 Hattenbach LO, Wellermann G, Steinkamp GW, Scharrer I, Koch FH, Ohrloff C: Visual outcome after treatment with low-dose recombinant tissue plasminogen activator or hemodilution in ischemic central retinal vein occlusion. Ophthalmologica 1999;213: 360-366.

82 Glacet-Bernard A, Zourdani A, Milhoub M, Maraqua N, Coscas G, Soubrane G: Effect of isovolemic hemodilution in central retinal vein occlusion. Graefes Arch Clin Exp Ophthalmol 2001;239:909-914.

83 Glacet-Bernard A, Atassi M, Fardeau C, Romanet JP, Tonini M, Conrath J, Denis P, Mauget-Faÿsse M, Coscas G, Soubrane G, Souied E: Hemodilution therapy using automated erythrocytapheresis in central retinal vein occlusion: results of a multicenter randomized controlled study. Graefes Arch Clin Exp Ophthalmol 2010, E-pub ahead of print.

- 84 Brown DM, Campochiaro PA, Singh RP, Li Z, Gray S, Saroj N, Rundle AC, Rubio RG, Murahashi WY, CRUISE Investigators: Ranibizumab for macular edema following central retinal vein occlusion: six-month primary end point results of a phase III study. Ophthalmology 2010;117:1124-1133e1.

85 Campochiaro PA, Heier JS, Feiner L, Gray S, Saroj N, Rundle AC, Murahashi WY, Rubio RG, BRAVO Investigators: Ranibizumab for macular edema following branch retinal vein occlusion: six-month primary end point results of a phase III study. Ophthalmology 2010;117:1102-1112. 
86 Hayreh SS: Management of central retinal vein occlusion. Ophthalmologica 2003;217: 167-188.

87 Coscas G, Coscas F, Vismara S, Zourdani A, Li Calzi C: Bright hyper-reflective spots and dense zones; in Coscas G (ed): Optical Coherence Tomography in Age-Related Macular Degeneration. Heidelberg, Springer, 2009, chapt 7, pp 159-167.

-88 Central Vein Occlusion Study Group: Evaluation of grid pattern photocoagulation for macular edema in central vein occlusion. Ophthalmology 1995;102:1425-1433.

- 89 Scott IU, Ip MS, VanVeldhuisen PC, Oden NL, Blodi BA, Fisher M, Chan CK, Gonzalez VH, Singerman LJ, Tolentino M, SCORE Study Research Group: A randomized trial comparing the efficacy and safety of intravitreal triamcinolone with standard care to treat vision loss associated with macular edema secondary to branch retinal vein occlusion: the Standard Care versus Corticosteroid for Retinal Vein Occlusion (SCORE) study report 6. Arch Ophthalmol 2009;127: 1115-1128, erratum 1655.

90 Ip MS, Scott IU, VanVeldhuisen PC, Oden NL, Blodi BA, Fisher M, Singerman LJ, Tolentino M, Chan CK, Gonzalez VH, SCORE Study Research Group: A randomized trial comparing the efficacy and safety of intravitreal triamcinolone with observation to treat vision loss associated with macular edema secondary to central retinal vein occlusion: the Standard Care versus Corticosteroid for Retinal Vein Occlusion (SCORE) study report 5. Arch Ophthalmol 2009;127: 1101-1114.

91 Ferrara DC, Koizumi H, Spaide RF: Early bevacizumab treatment of central retinal vein occlusion. Am J Ophthalmol 2007;144:864871.

92 Figueroa MS, Contreras I, Noval S, Arruabarrena C: Results of bevacizumab as the primary treatment for retinal vein occlusion. Br J Ophthalmol 2010;94:1052-1056.

-93 Wroblewski JJ, Wells JA 3rd, Adamis AP, Buggage RR, Cunningham ET Jr, Goldbaum M, Guyer DR, Katz B, Altaweel MM: Pegaptanib in Central Retinal Vein Occlusion Study Group: pegaptanib sodium for macular edema secondary to central retinal vein occlusion. Arch Ophthalmol 2009;127:374380

94 Sadda S, Danis R, Jico J, Li X-Y: Vascular changes in patients treated with dexamethasone intravitreal implant for macular edema due to BRVO or CRVO over 12 months. Poster presented at the Joint Meeting of the American Academy of Ophthalmology and the Middle East Africa Council of Ophthalmology (MEACO), Chicago, 2010.

95 Browning DJ, Scott AQ, Peterson CB, Warnock J, Zhang Z: The risk of missing angle neovascularization by omitting screening gonioscopy in acute central retinal vein occlusion. Ophthalmology 1998;105:776-784.
-96 Beutel J, Peters S, Lüke M, Aisenbrey S, Szurman P, Spitzer MS, Yoeruek E, Bevacizumab Study Group, Grisanti S: Bevacizumab as adjuvant for neovascular glaucoma. Acta Ophthalmol 2010;88:103-109.

-97 Moraczewski AL, Lee RK, Palmberg PF, Rosenfeld PJ, Feuer WJ: Outcomes of treatment of neovascular glaucoma with intravitreal bevacizumab. $\mathrm{Br} \mathrm{J}$ Ophthalmol 2009;93:589-593.

98 Parodi MB, Friberg TR, Pedio M, Fiotti N, di Stefano G, Ravalico G: Panretinal photocoagulation and photodynamic therapy for anterior segment neovascularization secondary to ischemic central retinal vein occlusion. Ophthalmic Surg Lasers Imaging 2007;38:94-99.

$\$ 99$ Battaglia Parodi M, Saviano S, Ravalico G: Grid laser treatment in macular branch retinal vein occlusion. Graefes Arch Clin Exp Ophthalmol 1999;237:1024-1027.

100 Rosenfeld PJ, Moshfeghi AA, Puliafito CA: Optical coherence tomography findings after an intravitreal injection of bevacizumab (Avastin) for neovascular age-related macular degeneration. Ophthalmic Surg Lasers Imaging 2005;36:331-335.

101 Iturralde D, Spaide RF, Meyrele CB, Klancnik JM, Yannuzzi LA, Fisher YL, Sorenson J, Slakter JS, Freund KB, Cooney M, Fine HF: Intravitreal bevacizumab (Avastin) treatment of macular edema in central retinal vein occlusion: a short-term study. Retina 2006;26:279-284.

102 Jaissle GB, Ziemssen F, Petermeier K, Szurman P, Ladewig M, Gelisken F, Voelker M, Holz FG, Bartz-Schmidt KU: Bevacizumab zur Therapie des sekundären Makulaödems nach venösen Gefässverschlüssen. Ophthalmologe 2006;103:471-475.

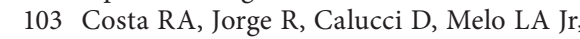
Cardillo JA, Scott IU: Intravitreal bevacizumab (Avastin) for central and hemicentral retinal vein occlusions: $\mathrm{IBeVO}$ study. Retina 2007;27:141-149.

104 Matsumoto Y, Freund KB, Peiretti E, Cooney MJ, Ferrara DC, Yannuzzi LA: Rebound macular edema following bevacizumab (Avastin) therapy for retinal venous occlusive disease. Retina 2007;27: 426-431.

105 Rabena MD, Pieramici DJ, Castellarin AA, Nasir MA, Avery RL: Intravitreal bevacizumab (Avastin) in the treatment of macular edema secondary to branch retinal vein occlusion. Retina 2007;27:419-425.

106 Spandau UH, Ihloff AK, Jonas JB: Intravitreal bevacizumab treatment of macular oedema due to central retinal vein occlusion. Acta Ophthalmol 2006;84:555-556.

107 Rosenfeld PJ, Fung AE, Puliafito CA: Optical coherence tomography findings after an intravitreal injection of bevacizumab (Avastin) for macular edema from central retinal vein occlusion. Ophthalmic Surg Lasers Imaging 2005;36:336-339.
108 Koizumi H, Ferrara DC, Bruè C, Spaide RF: Central retinal vein occlusion case-control study. Am J Ophthalmol 2007;144:858863.

109 McIntosh RL, Mohamed Q, Saw SM, Wong TY: Interventions for branch retinal vein occlusion: an evidence-based systematic review. Ophthalmology 2007;114:835854.

110 Arevalo JF, Garcia RA, Wu L, Rodriguez FJ, Dalma-Weiszhausz J, Quiroz-Mercado H, Morales-Canton V, Roca JA, Berrocal MH, Graue-Wiechers F, Robledo V, Pan-American Collaborative Retina Study Group: Radial optic neurotomy for central retinal vein occlusion: results of the Pan-American Collaborative Retina Study Group (PACORES). Retina 2008;28:1044-1052.

111 Spaide RF, Klancnik JM Jr, Gross NE: Retinal choroidal collateral circulation after radial optic neurotomy correlated with the lessening of macular oedema. Retina 2004; 24:356-359.

112 Garcia-Arumi J, Martinez-Castillo V, Boixadera A, Blasco H, Corcostegui B: Management of macular edema in branch retinal vein occlusion with sheathotomy and recombinant tissue plasminogen activator. Retina 2004;24:530-540.

113 Opremcak EM, Bruce RA, Lomeo MD, Ridenour CD, Letson AD, Rehmar AJ: Radial optic neurotomy for central retinal vein occlusion: a retrospective pilot study of 11 consecutive cases. Retina 2001;21: 408-415.

- 114 Hasselbach HC, Ruefer F, Feltgen N, Schneider U, Bopp S, Hansen LL, Hoerauf H, Bartz-Schmidt U, Roider J: Treatment of central retinal vein occlusion by radial optic neurotomy in 107 cases. Graefes Arch Clin Exp Ophthalmol 2007;245: 1145-1156.

115 Williamson TH, Poon W, Whitefield L, Strothidis N, Jaycock P: A pilot study of pars plana vitrectomy, intraocular gas and radial neurotomy in ischaemic central retinal vein occlusion. Br J Ophthalmol 2003; 87:1126-1129.

116 Nomoto H, Shiraga F, Yamaji H, Kageyama M, Takenaka H, Baba T, Tsuchida Y: Evaluation of radial optic neurotomy for central retinal vein occlusion by indocyanine green videoangiography and image analysis. Am J Ophthalmol 2004;138:612619.

- 117 Opremcak EM, Rehmar AJ, Ridenour CD, Kurz DE: Radial optic neurotomy for central retinal vein occlusion: 117 consecutive cases. Retina 2006;26:297-305.

- 118 Opremcak EM, Rehmar AJ, Ridenour CD, Kurz DE, Borkowski LM: Radial optic neurotomy with adjunctive intraocular triamcinolone for central retinal vein occlusion: 63 consecutive cases. Retina 2006;26: 306-313. 
-119 Fortunato P, Pollazzi L, Baroni M, Evangelisti A, la Torre A: Venous retinal flow reperfusion mechanisms following radial optic neurotomy with adjunctive intraocular triamcinolone in central retinal vein occlusion. Graefes Arch Clin Exp Ophthalmol 2010;248:167-173.

-120 Martinez-Jardon CS, Meza-de Regil A, Dalma-Weiszhausz J, Leizaola-Fernandez C, Morales-Canton V, Guerrero-Naranjo JL, Quiroz-Mercado H: Radial optic neurotomy for ischaemic central vein occlusion. Br J Ophthalmol 2005;89:558561.

-121 Patelli F, Radice P, Zumbo G, Fasolino G, Marchi S: Optical coherence tomography evaluation of macular oedema after radial optic neurotomy in patients affected by central retinal vein occlusion. Semin Ophthalmol 2004;19:21-24.

-122 Tsujikawa A, Hangai M, Kikuchi M, Ishida K, Kurimoto Y: Visual field defect after radial optic neurotomy for central retinal vein occlusion. Jpn J Ophthalmol 2006;50: 158-160.

-123 McAllister IL, Douglas JP, Constable IJ, Yu DY: Laser-induced chorioretinal venous anastomosis for non-ischaemic central retinal vein occlusion: evaluation of the complications and their risk factors. Am J Ophthalmol 1998;126:219-229.

-124 Peyman GA, Kishore K, Conway MD: Surgical chorioretinal venous anastomosis for ischemic central retinal vein occlusion. Ophthalmic Surg Lasers 1999;30:605-614.

125 Sharma A, D’Amico D: Medical and surgical management of central retinal vein occlusion. Int Ophthalmol Clin 2004;44:1-16.

-126 Quiroz-Mercado H, Sanchez-Buenfil E, Guerrero-Naranjo JL, Ochoa-Contreras D, Ruiz-Cruz M, Marcellino G, Damico DJ: Successful erbium:YAG laser-induced chorioretinal venous anastomosis for the management of ischaemic central retinal vein occlusion: a report of two cases. Graefes Arch Clin Exp Ophthalmol 2001;239:872875.

-127 Mirshahi A, Roohipoor R, Lashay A, Mohammadi SF, Mansouri MR: Surgical induction of chorioretinal venous anastomosis in ischaemic central retinal vein occlusion: a non-randomized controlled clinical trial. Br J Ophthalmol 2005;89:64-69.

- 128 Koizumi K, Nishiura M, Yamamoto T, Machida T, Nakamura T, Ouchi M, Kinoshita S: Intentional complete interruption of a retinal vein after vitrectomy might improve the rate of successful chorioretinal venous anastomosis formation in central retinal vein occlusion. Graefes Arch Clin Exp Ophthalmol 2002;240:787-794.
129 Furino C, Ferrari TM, Boscia F, Cardascia N, Sborgia L, Reibald M, Ferreri P, Sborgia $\mathrm{C}$ : Combined radial optic neurotomy, internal limiting membrane peeling, and intravitreal triamcinolone acetonide for central retinal vein occlusion. Ophthalmic Surg Lasers Imaging 2005;36:422-425.

130 Liang XL, Chen HY, Huang YS, Eong KGA, Yu SS, Liu X, Yan H: Pars plana vitrectomy and internal limiting membrane peeling for macular oedema secondary to retinal vein occlusion: a pilot study. Ann Acad Med Singapore 2007;36:293-297.

131 Mandelcorn MS, Nrusimhadevara RK: Internal limiting membrane peeling for decompression of macular oedema in retinal vein occlusion: a report of 14 cases. Retina 2004;24:348-355.

132 Park DH, Kim IT: Long-term effects of vitrectomy and internal limiting membrane peeling for macular edema secondary to central retinal vein occlusion and hemiretinal vein occlusion. Retina 2010;30:117124.

133 Nkeme J, Glacet-Bernard A, Gnikpingo K, Zourdani A, Mimoun G, Mahiddine H, Gkoritsa A, Tchamo A, Coscas G, Soubrane G: Surgical treatment of persistent macular edema in retinal vein occlusion. J Fr Ophthalmol 2006;29:808-814.

-134 Kumagai K, Furukawa M, Ogino N, Uemura A, Larson E: Long-term outcomes of vitrectomy with or without arteriovenous sheathotomy in branch retinal vein occlusion. Retina 2007;27:49-54.

135 Kumagai K, Furukawa M, Ogino N, Larson E, Uemura A: Long-term visual outcomes after vitrectomy for macular edema with foveal hemorrhage in branch retinal vein occlusion. Retina 2007;27:584-588.

136 Berker N, Batman C: Surgical treatment of central retinal vein occlusion. Acta Ophthalmol 2008;86:245-252.

137 DeCroos FC, Shuler RK Jr, Stinnett S, Fekrat S: Pars plana vitrectomy, internal limiting membrane peeling, and panretinal endophotocoagulation for macular edema secondary to central retinal vein occlusion. Am J Ophthalmol 2009;147:627-633e1.

138 Lu N, Wang NL, Wang GL, Li XW, Wang Y: Vitreous surgery with direct central retinal artery massage for central retinal artery occlusion. Eye (Lond) 2009;23:867-872.

139 Uemura A, Yamamoto S, Sato E, Sugawara T, Mitamura Y, Mizunoya S: Vitrectomy alone versus vitrectomy with simultaneous intravitreal injection of triamcinolone for macular edema associated with branch retinal vein occlusion. Ophthalmic Surg Lasers Imaging 2009;40:6-12.

140 Arai M, Yamamoto S, Mitamura Y, Sato E, Sugawara T, Mizunoya S: Efficacy of vitrectomy and internal limiting membrane removal for macular edema associated with branch retinal vein occlusion. Ophthalmologica 2008;223:172-176.
141 Oh IK, Kim S, Oh J, Huh K: Long-term visual outcome of arteriovenous adventitial sheathotomy on branch retinal vein occlusion induced macular edema. Korean J Ophthalmol 2008;22:1-5.

142 Funatsu H, Yamashita H, Ikeda T, Mimura T, Eguchi S, Hori S: Vitreous levels of interleukin- 6 and vascular endothelial growth factor are related to diabetic macular oedema. Ophthalmology 2003;110:1690-1696.

143 Funatsu H, Yamashita H, Ikeda T, Mimura T, Shimizu E, Hori S: Relation of diabetic macular oedema to cytokines and posterior vitreous detachment. Am J Ophthalmol 2003;135:321-327.

144 Saika S, Tanaka T, Miyamoto T, Ohnishi Y: Surgical posterior vitreous detachment combined with gas/air tamponade for treating macular oedema associated with branch retinal vein occlusion: retinal tomography and visual outcome. Graefes Arch Clin Exp Ophthalmol 2001;239:729732 .

145 Noma H, Funatsu H, Sakata K, Mimura T, Hori S: Macular microcirculation before and after vitrectomy for macular edema with branch retinal vein occlusion. Graefes Arch Clin Exp Ophthalmol 2010;248:443445.

146 Radetzky S, Walter P, Fauser S, Koizumi K, Kirchhof B, Joussen AM: Visual outcome of patients with macular edema after pars plana vitrectomy and indocyanine greenassisted peeling of the internal limiting membrane. Graefes Arch Clin Exp Ophthalmol 2004;242:273-278.

147 Weiss JN, Bynoe LA: Injection of tissue plasminogen activator into a branch retinal vein in eyes with central retinal vein occlusion. Ophthalmology 2001;108:2249-2257.

148 Feltgen N, Junker B, Agostini H, Hansen LL: Retinal endovascular lysis in ischaemic central retinal vein occlusion: one-year results of a pilot study. Ophthalmology 2007; 114:716-723.

149 Osterloh MD, Charles S: Surgical decompression of branch retinal vein occlusion. Arch Ophthalmol 1988;106:1469-1471.

150 Avci R, Inan UU, Kaderli B: Evaluation of arteriovenous crossing sheathotomy for decompression of branch retinal vein occlusion. Eye (Lond) 2008;22:120-127.

151 Chung EJ, Lee H, Koh HJ: Arteriovenous crossing sheathotomy versus intravitreal triamcinolone acetonide injection for treatment of macular edema associated with branch retinal vein occlusion. Graefes Arch Clin Exp Ophthalmol 2008;246:967-974.

152 NICE Interventional Procedure Guidance IPG334: Arteriovenous crossing sheathotomy for branch retinal vein occlusion. 2010. http://guidance.nice.org.uk/IPG334 (accessed September 22, 2010). 